\title{
Evaluating Warm and Cold Rain Processes in Cloud Microphysical Schemes Using OLYMPEX Field Measurements
}

\author{
AARON R. NAEGER \\ Earth System Science Center, University of Alabama in Huntsville, Huntsville, Alabama \\ BRIAN A. COLLE AND NA ZHOU \\ School of Marine and Atmospheric Sciences, Stony Brook University, State University of New York, Stony Brook, New York \\ ANDREW MOLTHAN \\ Earth Science Office, NASA Marshall Space Flight Center, Huntsville, Alabama
}

(Manuscript received 27 March 2019, in final form 29 January 2020)

\begin{abstract}
Field observations from the Olympic Mountain Experiment (OLYMPEX) around western Washington State during two atmospheric river (AR) events in November 2015 were used to evaluate several bulk microphysical parameterizations (BMPs) within the Weather Research and Forecasting (WRF) Model. These AR events were characterized by a prefrontal period of stable, terrain-blocked flow with an abundance of cold rain over the lowland region followed by less stable, unblocked flow with more warm rain, and a shift in the largest precipitation amounts to over the windward Olympic slopes. Our WRF simulations underpredicted the precipitation by $19 \%-36 \%$ in the Morrison (MORR) and Thompson (THOM) BMPs and $10 \%-23 \%$ in the predicted particle properties (P3) BMP, with the largest underpredictions over the windward slopes during the more convective, unblocked flow conditions. Several important processes related to the BMPs led to the differences in simulated precipitation. First, the prognostic single ice category parameterization in the $\mathrm{P} 3$ scheme promoted a more realistic evolution of rimed particles and larger cold rain production, which led to the lowest underpredictions in precipitation among the schemes. Second, efficient melting processes associated with the production of nonspherical ice and snow in the P3 and THOM BMPs, respectively, promoted a more realistic transition to rain fall speeds within the warm layer compared to the spherical snow assumption in MORR. Last, all BMPs underpredict the contribution of warm rain processes to the surface precipitation, particularly during the unblocked flow period, which may be partly explained by too weak condensational and collisional growth processes due to the neglect of turbulence parameterizations within the schemes.
\end{abstract}

\section{Introduction}

Bulk microphysical parameterization (BMP) schemes are a critical component of operational weather forecasting models, as they must simulate the formation and development of hydrometeor species, including their interaction, growth, and precipitation processes. Thus, model performance and precipitation forecasts can be strongly dependent on the parameterizations and assumptions used to represent these complex processes within the BMPs (Lin and Colle 2009; Morrison et al. 2009; Milbrandt et al. 2010; Molthan and Colle 2012;

Corresponding author: Dr. Aaron R. Naeger, aaron.naeger@ nasa.gov
Lang et al. 2014; Naeger et al. 2017). A wealth of validation efforts have documented deficiencies and biases in the parameterizations and assumptions within BMPs (Hong et al. 2010; Shi et al. 2010; Molthan and Colle 2012; Naeger et al. 2017), which has led to the development and implementation of more advanced BMPs in forecasting models (Lin and Colle 2011; Morrison and Milbrandt 2015). Early BMPs were all single moment schemes, which were found to have large biases given the fixed parameter assumptions applied to the predefined hydrometeor classes (Molthan and Colle 2012). As a result, several double-moment schemes have been implemented into the Weather Research and Forecasting (WRF; Skamarock et al. 2008) Model over the past decade, such as the Thompson (THOM), 
Morrison (MORR), and the most recent predicted particle properties (P3) scheme. Detailed discussion of these BMPs is presented in section 2c.

Precipitation and flood forecasts have been shown to be dependent on the choice of BMP within a model (e.g., Colle and Mass 2000; Liu and Moncrieff 2007; Halder et al. 2015; Naeger et al. 2017), For these extreme flooding events from atmospheric rivers (ARs; Ralph et al. 2006; Dettinger 2011), it was found that total precipitation from operational models can be underestimated by as much as $50 \%$ (Ralph et al. 2010). Flood-producing ARs typically feature orographically enhanced precipitation (Neiman et al. 2011), which can be related to the development of small-scale turbulent cells over the windward slope of mountain barriers (Houze and Medina 2005). For heavy precipitation events over the Pacific Northwest, Colle et al. (2000) highlighted a large underprediction of precipitation over the lowland and windward slopes for an operational model with 4-km resolution. Minder et al. (2008) also found large errors in precipitation forecasts for major storms impacting the Olympic Mountains, which they partly attributed to initial conditions, in addition to choice of BMP and model resolution. Martin et al. (2018) attributed precipitation deficiencies for AR simulations from the WRF Model to low biases in the low-level water vapor flux. Thus, there remains a strong need to improve forecasts of extreme precipitation events such as ARs in an effort to mitigate flood risk and damage from these storms.

The suite of intensive instrumentation deployed during the recent Olympic Mountains Experiment (OLYMPEX), which focused on the Olympic Peninsula of Washington State from November 2015 to February 2016, provides an excellent opportunity to better understand orographic precipitation processes associated with ARs and midlatitude cyclones (Houze et al. 2017). Zagrodnik et al. (2018) analyzed gauges and disdrometers located from the coast to windward slopes during a strong AR event from 12 to 13 November 2015, in which there were large concentrations of small to medium raindrops, in addition to highly varying concentrations of large drops, suggesting both warm rain (e.g., collision-coalescence) and cold rain processes (e.g., melting). Purnell and Kirshbaum (2018) noted the presence of cold rain via an active seederfeeder process during warm frontal and sector conditions throughout OLYMPEX from the synthesis of observations and model simulations in which "seeder" clouds initiate precipitation growth that falls into orographically enhanced ("feeder") clouds at lower levels (Cotton et al. 2011). McMurdie et al. (2018) provided further evidence of this seeder-feeder process after documenting a larger reflectivity signature above the melting layer over the windward slopes compared to the ocean throughout OLYMPEX. Similar to earlier studies, Conrick and Mass (2019) highlighted a significant underprediction of precipitation totals for AR events, including 12-13 November, from several WRF BMPs, while noting the possible deficiency of the WRF Model in simulating warm rain processes.

In this study, we simulated AR events between 12-13 and 16-17 November 2015 that were both characterized by a warm prefrontal period with stable, blocked flow followed by less stable, unblocked flow. Recent studies have documented important features within the ARs during OLYMPEX (Zagrodnik et al. 2018; McMurdie et al. 2018; Conrick et al. 2018; Conrick and Mass 2019), but more detailed modeling analyses are needed to fully evaluate and improve the performance of BMPs for these heavy precipitation events. Thus, our intensive validation effort here aims to improve our understanding of the microphysical processes that contribute to cold and warm rain production within the $\mathrm{P} 3$, MORR, and THOM schemes during ARs by addressing the following motivational questions:

1) How do different BMP assumptions impact the simulated precipitation amounts for heavy orographic precipitation events?

2) How does BMP performance change as the low-level temperatures increase and the flow transitions from blocked to unblocked flow by the terrain?

3) What are the important microphysical processes causing the precipitation differences during the blocked and unblocked flow periods?

The P3, MORR, and THOM schemes are attractive BMPs to evaluate in this study, as they apply unique parameterizations for simulating frozen hydrometeor processes, which impact both cold and warm rain production, and consequently, precipitation accumulation at the surface. Our BMP evaluation can also directly benefit the operational weather forecasting community, as the $2.5-\mathrm{km}$ High-Resolution Deterministic Prediction System (HRDPS) in Canada (Milbrandt et al. 2016) and the 3-km High-Resolution Rapid Refresh (HRRR) model managed at the NOAA/National Centers for Environmental Prediction (NCEP; Pinto et al. 2015) utilize the P3 and THOM BMPs, respectively.

\section{Data and methods}

\section{a. OLYMPEX field instrumentation}

Figure 1a presents an elevation map and instrumentation for the OLYMPEX field campaign (Houze et al. 2017). We analyze plan position indicator (PPI) and range-height indicator (RHI) scans from the NASA 


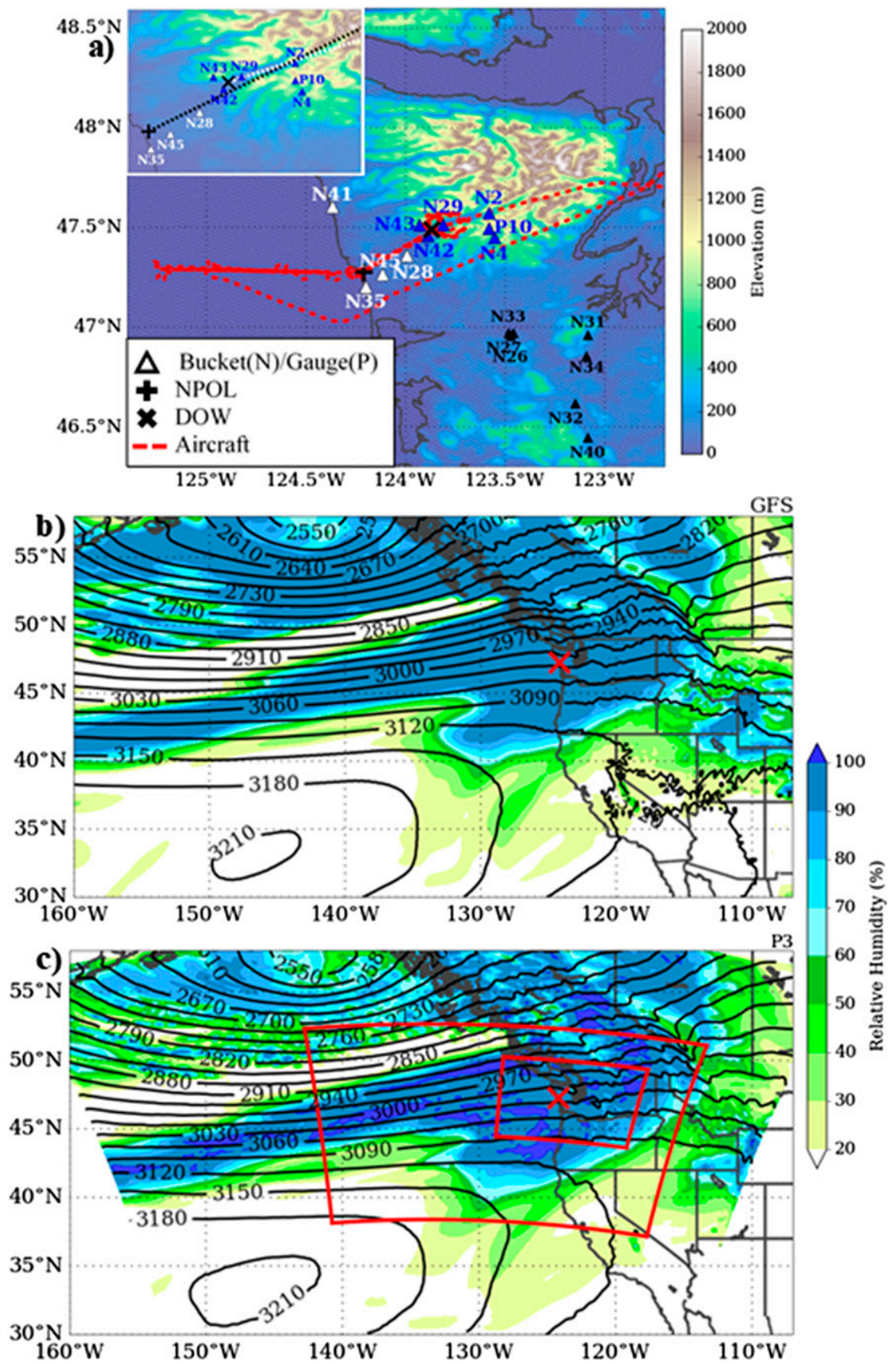

FIG. 1. (a) Terrain elevation (shaded) from WRF 1-km grid, aircraft track (dashed red), and site locations (diamonds) with quality-assured precipitation measurements during 12-13 Nov case. NASA ("N") tipping buckets and Pluvio ("P") weighting gauges were separated into lowland and windward site locations according to the white and blue triangles, NPOL and DOW at black cross and $\times$ locations, respectively. Inset (top left) shows zoom in of NPOL and DOW locations and RHI azimuthal scans of $54^{\circ}$ and $64^{\circ}$ from NPOL (dashed black) and DOW (dashed white), respectively. (b) GFS vs (c) P3 RH and geopotential heights from the WRF 9-km grid at 0000 UTC 13 Nov. WRF 3- and 1-km grid locations shown in red and OLYMPEX field site denoted by red $\times$. 
S-band radar (NPOL; Wolff et al. 2017) at the coast and X-band Doppler on Wheels (DOW; Houze et al. 2018) along the windward slopes for evaluating the simulated precipitation structures from the BMPs. Eddy dissipation rate (EDR) is calculated based on spectrum width measurements from NPOL (Bohne 1982) using the Python Turbulence Detection Algorithm (Lang and Guy 2017) for detecting turbulent motions. The dual-polarization measurements are also used within a threshold-based algorithm for classifying hydrometeor types (Dolan et al. 2013), which we utilize in this study. We supplement the PPI scans from NPOL with dual-polarimetric S-band Weather Surveillance Radar-1988 Dopplers (WSR-88Ds) at Seattle/Tacoma, Washington (KATX); Langley Hill, Washington (KLGX); and Portland, Oregon (KRTX), for constructing $0.01^{\circ}$ resolution composite maps. To generate the composite maps, the reflectivity from the $0.4^{\circ}-0.6^{\circ}$ elevation scans from the NPOL and WSR-88Ds are regridded onto a $0.01^{\circ} \times 0.01^{\circ}$ grid, where we show the maximum reflectivity at each grid point. For this study, we utilize the RHI azimuthal scans at $54^{\circ}$ and $64^{\circ}$ from the NPOL and DOW radars, respectively, due to their alignment with the University of North Dakota (UND) aircraft track and Quinault Valley region (see inset to Fig. 1a).

Colorado State University (CSU) sounding launches at the NPOL site evaluated the thermodynamic and dynamic structure within the model (Rutledge et al. 2018). We also use quality-controlled precipitation measurements from the NASA tipping-bucket rain gauges (Petersen et al. 2017c) and Pluvio-2 weighting gauges (Petersen et al. 2017a), which are denoted by "N" and "P" in Fig. 1a, for validating the accumulated precipitation from the BMPs. For purposes of this study, the tipping buckets and weighting gauges were separated into lowland and windward site locations as shown by the white and blue triangles, respectively, in Fig. 1a.

For observing hydrometeor properties, mass-weighted mean rain diameters $\left(D_{m}\right)$ from the Automated Parsivel Unit (APU) level 3 dataset at the lowland Fishery (N28) and windward Bishop/CRN (N29) sites were used for evaluating the simulated rainfall properties within the BMPs (Petersen et al. 2017b). Droplets with fall speeds outside of a generally accepted $\pm 50 \%$ range in terminal fall speed were eliminated for processing of the level 3 dataset (Tokay et al. 2014), which consists of integrating the raw 10-s data into 1-min values. The APU has uncertainties of up to $27 \%$ for large $D_{m}>1.75 \mathrm{~mm}$ and less than $8 \%$ for $D_{m}<1 \mathrm{~mm}$ (Jaffrain and Berne 2011). The Fishery and Bishop/CRN sites were also equipped with a $24 \mathrm{GHz}$ (K-band) Micro Rain Radar (MRR) capable of measuring vertical profiles of liquid water content and fall speed at $100-\mathrm{m}$ resolution and up to 3-km height every 10 s (Petersen and Gatlin 2017). For validating the WRF BMPs, we use the level 2 time-averaged profiles at 1-min frequency, with small uncertainties for vertical motions less than $2 \mathrm{~m} \mathrm{~s}^{-1}$ (Peters et al. 2005). Note the lowland Fishery and windward Bishop/CRN sites are conveniently located along the NPOL and DOW RHI scans. Last, the UND Cessna Citation II aircraft was equipped with a two-dimensional optical array cloud probe (2D-C; Heymsfield et al. 2017) and highvolume particle spectrometer (HVPS) for permitting retrievals of ice particle number concentrations for 41 size bins ranging from 0.04 to $30 \mathrm{~mm}$ (Poellot et al. 2017). We derived $D_{m}$ from the ice number concentrations using the Heymsfield et al. (2004) methodology, which is valid for snow aggregates, and particles smaller than $100 \mu \mathrm{m}$ were disregarded due to large uncertainties in the sample area of the probe (Strapp et al. 2001). Shapes, sizes, and ice habits of precipitation particles aloft were diagnosed via images from the 2D-C. King and Nevzorov probes were also onboard the aircraft for measuring cloud liquid water content (LWC) and ice water content (IWC), respectively. Altogether, these aircraft instruments permitted a detailed evaluation of the hydrometeor properties within the BMPs.

\section{b. Model setup}

We conducted 36-h WRF (version 3.7.1) simulations with 50 vertical levels using a 9-3-1 km one-way nested domain configuration focused on the OLYMPEX field site (i.e., Fig. 1c). Vertical grid spacing increased from about $60 \mathrm{~m}$ near the surface to $240 \mathrm{~m}$ at $2 \mathrm{~km}$ in height. Forecasts were initialized at 1200 UTC 12 November 2015 with initial and lateral boundary conditions provided by the 6-h Global Forecast System (GFS) reanalysis data at $0.25^{\circ}$ grid spacing. Other atmospheric analysis data, including the $20-\mathrm{km}$ Rapid Update Cycle, led to unrepresentative meteorological conditions and poorer agreement between the observed and simulated precipitation (not shown). The physics options included the Eta similarity (Janjić 1990), Noah model (Tewari et al. 2004), and Mellor-Yamada-Janjić (Janjić 1994) schemes for the surface layer, land surface, and planetary boundary layer (PBL), respectively, along with the Grell-Freitas ensemble cumulus parameterization ( $9 \mathrm{~km}$ grid only; Grell and Freitas 2014) and the Rapid Radiative Transfer Model for GCMs (RRTMG; Iacono et al. 2008). Same model options were selected for the P3, MORR, and THOM BMP simulations, and a constant cloud droplet number concentration of $100 \mathrm{~cm}^{-3}$ was assumed within all schemes. An identical model setup was used for the 16-17 November case, except that forecasts were 
initialized at 1200 UTC 16 November 2015. A summary of model options is shown in Table 1.

\section{c. Bulk microphysical parameterizations}

The Thompson (THOM) scheme is a partial doublemoment scheme, since it only predicts the number concentration for cloud ice and rain (Thompson et al. 2008). For characterizing snow, the THOM scheme uses relationships between particle size distribution moments and air temperature developed from an observational database from Field et al. (2005). The observed relationships between the predicted snow mass and air temperature allow for the calculation of higher-order moments for predicting the snow field evolution. For treating conversion of rimed snow to graupel, the THOM scheme applies a linear relationship between the riming to depositional growth ratio and graupel production. A variable intercept $\left(N_{o}\right)$ parameter is used for graupel to capture graupel-like snow and higher-density, faster falling hail in THOM.

As in THOM, the MORR scheme predicts cloud water, rain, ice, snow, and graupel, but is a full doublemoment scheme predicting mass and number concentrations for all hydrometeor classes (Morrison et al. 2009). Thus, particle size distributions for all hydrometeors in this "graupel" configuration of the MORR scheme can be characterized by a slope $(\lambda)$ and $N_{o}$ derived from the predicted mass and number concentration, instead of relying on temperature and snow mass relationships for diagnosing the snow intercept $\left(N_{o s}\right)$ as done in the THOM scheme. The prediction of snow number concentration in the MORR scheme has been shown to improve the representation of the aggregation process and associated snow sizes (Molthan and Colle 2012). For the multiple predefined ice-phase categories in MORR and THOM, constant terms characterize the particle properties, such as the $a_{m}$ and $b_{m}$ coefficients assigned for the particle effective density and fractal dimension, respectively, in the power law mass-diameter relationship $[m-D$; $\left.m(D)=a_{m} D^{b m}\right]$. These schemes also assign constant $a_{v}$ and $b_{v}$ coefficients for the ice crystal habit and degree of riming, respectively, in the terminal velocity-diameter relationship $\left[V-D ; V(D)=a_{v} D^{b v}\right]$. The abrupt transitions in particle properties within these schemes do not represent the smoothly varying properties observed in the atmosphere (Barthazy and Schefold 2006). Furthermore, the use of strict thresholds for converting between different ice-phase categories within the scheme, such as the cloud water threshold of $0.5 \mathrm{~g} \mathrm{~m}^{-3}$ for producing graupel from rimed snow in MORR, can lead to unrealistic model results (Naeger et al. 2017). For this study, we present reflectivity from standard WRF output for the MORR and THOM schemes,
TABLE 1. Configuration used in the WRF simulations.

\begin{tabular}{|c|c|c|c|}
\hline \multicolumn{4}{|c|}{ WRF configuration options } \\
\hline $\begin{array}{l}\text { Initial and boundary } \\
\text { condition data }\end{array}$ & \multicolumn{3}{|c|}{ GFS $0.25^{\circ}$, RAP $32 \mathrm{~km}$, NARR $32 \mathrm{~km}$} \\
\hline Vertical resolution & \multicolumn{3}{|l|}{50 Levels } \\
\hline PBL physics & \multicolumn{3}{|c|}{ Mellor-Yamada-Janjić } \\
\hline Surface layer & \multicolumn{3}{|c|}{ Eta similarity } \\
\hline Land surface & \multicolumn{3}{|l|}{ Noah } \\
\hline Cloud microphysics & \multicolumn{3}{|c|}{$\begin{array}{l}\text { Predicted particle properties (P3), } \\
\text { Morrison (MORR), Thompson } \\
\text { (THOM) }\end{array}$} \\
\hline Cumulus scheme & \multicolumn{3}{|c|}{ Grell-Freitas ensemble } \\
\hline SW radiation & \multicolumn{3}{|l|}{ RRTMG } \\
\hline LW radiation & \multicolumn{3}{|l|}{ RRTMG } \\
\hline Feedback & \multicolumn{3}{|l|}{ Turned off } \\
\hline Domains & Domain 1 & Domain 2 & Domain 3 \\
\hline Horizontal resolution & $9 \mathrm{~km}$ & $3 \mathrm{~km}$ & $1 \mathrm{~km}$ \\
\hline Grid points & $425 \times 365$ & $682 \times 532$ & $772 \times 649$ \\
\hline Cumulus scheme & Turned on & Turned off & Turned off \\
\hline Time step & $30 \mathrm{~s}$ & $10 \mathrm{~s}$ & $3.3 \mathrm{~s}$ \\
\hline
\end{tabular}

which assumes a distribution of liquid on ice particles based on snow and rain mixing ratios for representing bright bands.

The P3 scheme has a user-specified number of "free" ice-phase categories each of which can, in principle, represent any type of frozen hydrometeor. A complete description of the full scheme is presented in Morrison and Milbrandt (2015) and Milbrandt and Morrison (2016), with the single-ice category version of the $\mathrm{P} 3$ scheme used in this study (Morrison and Milbrandt 2015). The P3 ice category is represented by four prognostic mixing ratio variables of total ice mass $\left(q_{i}\right)$, rime ice mass $\left(q_{\text {rim }}\right)$, rime volume $\left(B_{\text {rim }}\right)$, and total ice number concentration $\left(N_{i}\right)$, within conservation equations. Predicted particle properties (e.g., rime mass fraction, bulk density, and mean particle size) are then derived from these equations, which allows properties to evolve continuously in time and space. The implementation of different $m-D$ relationships for small ice spheres, larger unrimed particles, and partially to fully rimed particles also permits more smoothly varying ice particle properties. For partially rimed ice particles in particular, the $m-D$ relationship is dependent on the predicted rime mass fraction $\left(F_{r}=\right.$ $\left.q_{\text {rim }} / q_{i}\right)$ and mean particle size $(D)$. The $V-D$ relationship in the $\mathrm{P} 3$ scheme incorporates $a_{v}$ and $b_{v}$ coefficients derived following Mitchell and Heymsfield (2005) that explicitly account for particle density, which is advantageous over most other BMPs, including MORR and THOM, that neglect an explicit dependence of fall speed on density. It was shown in Morrison et al. (2015) that the single ice category approach in $\mathrm{P} 3$ can realistically simulate a wide range of ice particle types, similar to traditional schemes with multiple predefined ice 
TABLE 2. Parameters defining relationships within each microphysics schemes. $M_{0 x}$ refers to the snow (MORR, THOM) and total ice (P3) number concentrations. For THOM, $M_{2}$ and $M_{3}$ refer to the second and third moment of the snow size distribution. In each scheme, the parameters $a_{m}$ and $b_{m}$, which characterize the particle effective density and particle fractal dimension, respectively, are necessary for determining the $M-D$ relationship $\left[m(D)=a_{m} D^{b m}\right]$, while the parameters $a_{v}$ and $b_{v}$, which vary with crystal habit and degree of riming, are necessary for determining the $V-D$ relationship $\left[V(D)=a_{v} D^{b v}\right.$. For MORR and THOM with separate graupel categories, the related graupel parameters are shown in second row. Note that $a_{m}$ is dependent on the predicted $\rho_{s}$ in $\mathrm{P} 3$, and that $a_{v}$ and $b_{v}$ are derived following Mitchell and Heymsfield (2005) based on the $R_{e}-X$ relationship, where $R_{e}$ is the particle Reynolds number and $X$ is the Best (Davies) number (related to the ratio of the particle mass to its projected area).

\begin{tabular}{llccccc}
\hline \hline Scheme & \multicolumn{1}{c}{$N_{o x}\left(\mathrm{~m}^{-4}\right)$} & $\mu_{x}$ & $\rho_{x}\left(\mathrm{~kg} \mathrm{~m}^{-3}\right)$ & $a_{m}\left(\mathrm{~kg} \mathrm{~m}^{-\mathrm{bm}}\right)$ & $b_{m}$ & $a_{v}\left(\mathrm{~m}^{1-b v} \mathrm{~s}^{-1}\right)$ \\
\hline P3 & $f\left(q_{i}, M_{0 i}\right)$ & Lookup table & Predicted & $\left(1 / 1-F_{r}\right) \alpha_{v a}$ & $\beta_{v a}$ & $f\left(R_{e}, X\right)$ \\
MORR & $f\left(M_{0 s}, \lambda_{s}\right)$ & 0 & 100 & $(\pi / 6) \rho x$ & 3 & 11.72 \\
& $f\left(M_{0 g}, \lambda_{g}\right)$ & 0 & 400 & & 3 & 0.3 \\
THOM & $f\left(M_{2}, M_{3}\right) f\left(q_{g}\right)$ & varies & $f(D)$ & 0.069 & 2 & 0.3 \\
& & 0 & 500 & $(\pi / 6) \rho g$ & 3 & 40 \\
\hline
\end{tabular}

categories. Furthermore, P3 has been shown to promote a more realistic time-varying spatial distribution of riming within precipitation bands, which can lead to more representative fall speeds and precipitation amounts (Colle et al. 2017; Naeger et al. 2017). For a highly relevant orographic precipitation case, Morrison et al. (2015) found that P3 simulated more precipitation over the windward slopes from producing areas of relatively fast-falling ice with rimed snow and graupel characteristics compared to the more snow-dominated MORR and THOM schemes. Contrary to MORR and THOM, P3 ignores the brightband approximation when calculating reflectivity in the scheme. Table 2 is the summary of the BMP specifications.

Throughout this paper we refer to warm rain as rain that originates from the warm-phase processes of autoconversion, rain condensation, and accretion of cloud liquid water by rain, while we refer to cold rain as rain that originates from the cold-phase processes of melting and shedding of precipitating ice particles (snow, rimed, or graupel). We note the limitation of separately classifying these processes as warm and cold rain, as the intensity of the warm-phase accretion processes can be strongly dependent on the cold rain production from above. Thus, the phrase "hybrid rain" is used in this paper to recognize conditions where both warm and cold rain processes appear active and significantly contributing to precipitation at the surface.

\section{Analysis of 12-13 November 2015 event}

\section{a. Large-scale setup and precipitation}

This AR event was characterized by relatively strong low-level moist flow impinging upon the Olympic Mountains that promoted large windward rain accumulations. At 0000 UTC 13 November (Fig. 1b), the GFS reanalysis showed a 700-hPa trough was over the Gulf of Alaska, along with a plume of moisture $(\mathrm{RH}>90 \%)$ from the central Pacific to the Pacific Northwest. At lower levels a950-hPa southwesterly jet $\left(25 \mathrm{~m} \mathrm{~s}^{-1}\right)$ associated with a warm front was advecting the warm, moist air toward the coast (Fig. 2a). The warm front propagated over the Olympic Peninsula by 1200 UTC 13 November, which led to a warming of up to $6^{\circ} \mathrm{C}$ over the windward slope (Fig. 2b). Our P3 simulation reproduce the moisture field (Fig. 1c) and warming trend over the Olympics associated with the simulated warm frontal passage (Figs. 2c,d).

The CSU NPOL soundings at approximately 2100 UTC 12 November and 0600 UTC 13 November reveal the transition from the stable warm-frontal conditions to less stable warm-sector conditions during the AR event (Purnell and Kirshbaum 2018). The 2100 UTC sounding showed a shallow layer of moist neutral conditions with southerly winds from near the surface to about $925 \mathrm{hPa}$, which was capped by a stable, warm frontal inversion layer with veering winds to $\sim 800 \mathrm{hPa}$ (Fig. 3a). By 0600 UTC, this transitioned to a moist neutral to convectively unstable environment, except for a stable layer between 850 and $800 \mathrm{hPa}$, with shallow layers of convective instability (i.e., decreasing saturation equivalent potential temperature $\left(\theta_{e}^{*}\right)$ with height) between 650 and $550 \mathrm{hPa}$ (Fig. 3b). The P3 scheme successfully reproduces the moist stable (Fig. 3c) and moist neutral conditions (Fig. 3d). For diagnosing the flow conditions over the Olympic barrier, we calculated the moist Froude number $\left(\mathrm{Fr}=U / N_{m} h\right)$ from the soundings following Durran and Klemp (1982), where $U$ is mean wind speed perpendicular to the barrier in the $1000-850 \mathrm{hPa}$ layer, $N_{m}$ is moist Brunt-Väisälä frequency $(1000-850 \mathrm{hPa}$ layer), and $h$ is the mountain height of $1800 \mathrm{~m}$ valid for Olympic Mountains. Both the observations and model show blocked flow conditions with $\mathrm{Fr}$ of about 0.5 at 2100 UTC that transition to unblocked flow by 0600 UTC with Fr of about 2.5, which agrees with the observational analysis in Purnell and Kirshbaum (2018). In agreement 
GFS

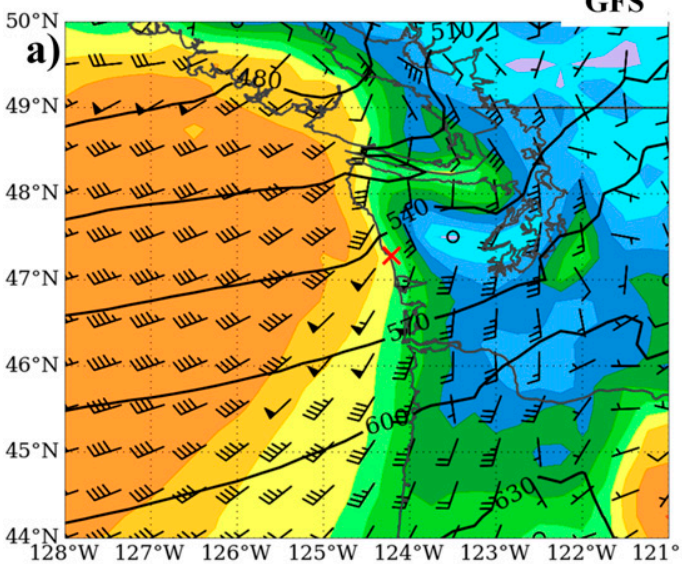

P3

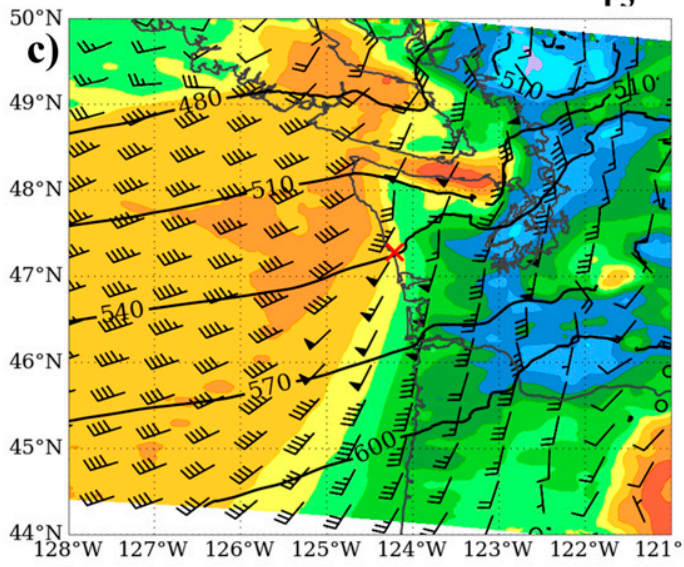

GFS

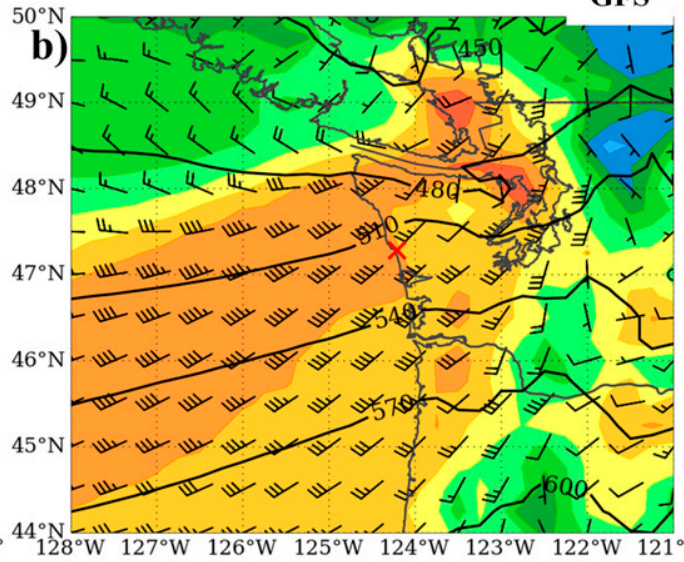

P3
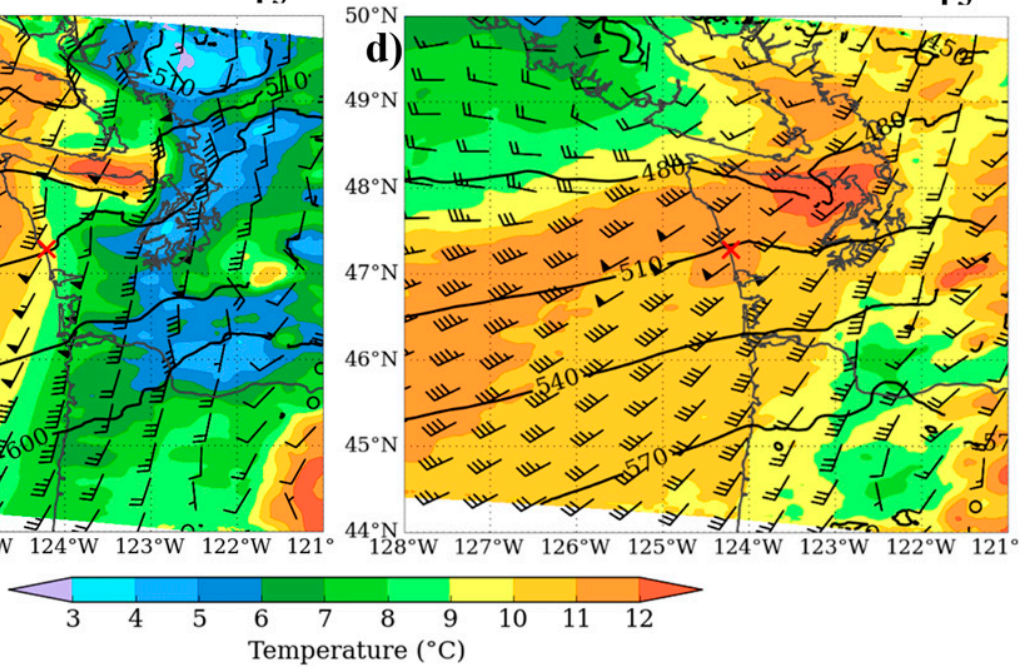

FIG. 2. GFS $950 \mathrm{hPa}$ temperature (shaded), geopotential heights (solid black, contoured every $30 \mathrm{~m}$ ), and winds [1 full barb $=10 \mathrm{kt}\left(1 \mathrm{kt} \approx 0.51 \mathrm{~m} \mathrm{~s}^{-1}\right)$ ] at (a) 0000 and (b) 1200 UTC 13 Nov 2015. (c),(d) As in (a),(b), but for P3 simulation results from the WRF 1-km grid.

with Zagrodnik et al. (2018), we found an increase in the vertically integrated moisture flux from 1000 to $700 \mathrm{hPa}$ calculated from the CSU sounding for these two time periods (540 and $610 \mathrm{~kg} \mathrm{~m}^{-1} \mathrm{~s}^{-1}$ ), along with comparable increases within our simulation (600 and $615 \mathrm{~kg} \mathrm{~m}^{-1} \mathrm{~s}^{-1}$ ). The MORR and THOM forecasts show very similar comparisons to the observed large-scale environmental conditions (not shown), which provides confidence that cloud and precipitation discrepancies between the BMPs are driven by the differences within the schemes.

Figure 4 highlights the observed accumulated precipitation for the combined lowland and windward site locations of over 400 and $1400 \mathrm{~m}$, respectively, for the 24-h period beginning 1800 UTC 12 November. By combining these locations, we are able to conduct a broader assessment of the simulated precipitation over these regions, while also mitigating the possibility of model displacement errors overwhelming the precipitation statistics, particularly over the terrain. We did not include the final $3 \mathrm{~h}$ of this 24 -h period when conducting our BMP evaluations, since the model was much too stable during the cold frontal passage over the Olympic Peninsula after 1500 UTC 13 November (not shown). Simulated precipitation was overall lower than the observed totals with underprediction that shifted from the lowland to windward slope during the event within all BMPs (Fig. 4). In particular, the MORR and THOM schemes show average underpredictions of about $25 \mathrm{~mm}$ over the lowland sites and 42 and $36 \mathrm{~mm}$ over the windward sites, respectively, while the $\mathrm{P} 3$ scheme shows smaller underpredictions of 11 and $25 \mathrm{~mm}$ over these regions (Table 3). For the stable, blocked (Fr $<1 ; 1800$ UTC 12 November -0200 UTC 13 November) and less stable, unblocked flow periods $(\mathrm{Fr}>1 ; 0200-1500$ UTC 13 November), corresponding underpredictions of about 13 and $26 \mathrm{~mm}$ occur within the P3 forecast and 

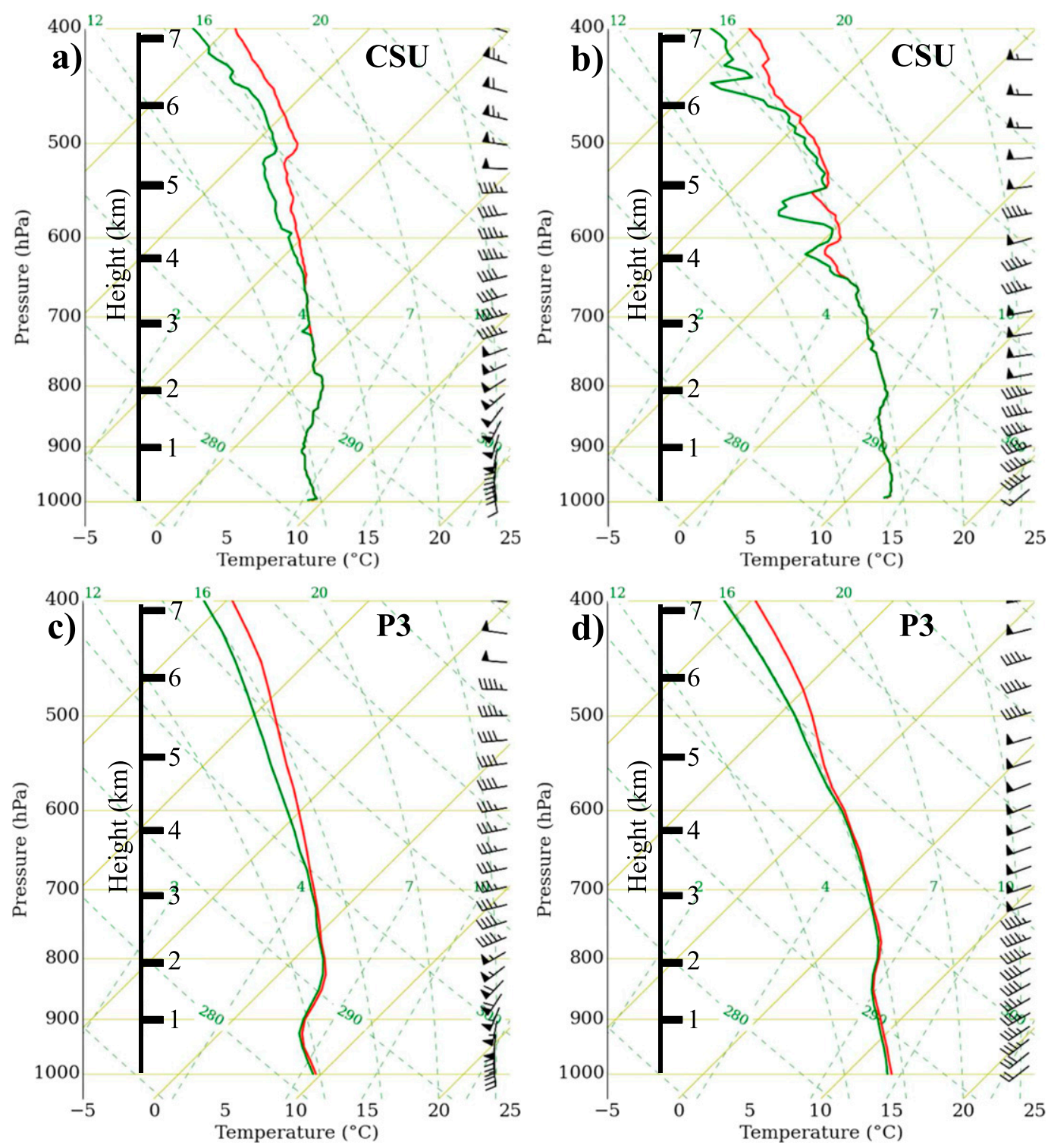

FIG. 3. CSU NPOL observed soundings at (a) 2100 UTC 12 Nov and (b) 0600 UTC 13 Nov. Model sounding from P3 simulation at (c) 2030 UTC 12 Nov and (d) 0530 UTC 13 Nov calculated by averaging the nearest 25 grid points to the NPOL site.

20 and $41 \mathrm{~mm}$ within both the MORR and THOM simulations (Table 4). Overall, relative precipitation deficits range between approximately $19 \%-36 \%$ in the MORR and THOM BMPs and $10 \%-23 \%$ in the P3 BMP, with the largest underpredictions over the windward slopes during the unblocked flow conditions.

During the 21-h forecast period from 1800 UTC 12 November to 1500 UTC 13 November (Fig. 5), the P3 simulates larger precipitation totals across the lowlands and windward slopes of the Olympic Peninsula (Fig. 5a), with a broad area exceeding $120 \mathrm{~mm}$ in rainfall extending farther to the west over the lowlands in P3 than in MORR (Fig. 5b) and THOM (Fig. 5c). THOM shows an improved forecast over the Olympic Peninsula compared to MORR, which leads to the reduction in the dry precipitation bias at many of the gauge sites, particularly the windward sites (Table 3). Conrick and Mass (2019) also noted a similar underprediction issue with WRF over the Olympic Peninsula for this event.

\section{b. Stable, blocked flow period over lowland region}

The radar reflectivity at 2100 UTC 12 November from the composite NPOL/NEXRAD PPI at $0.5^{\circ}$ elevation 
a)

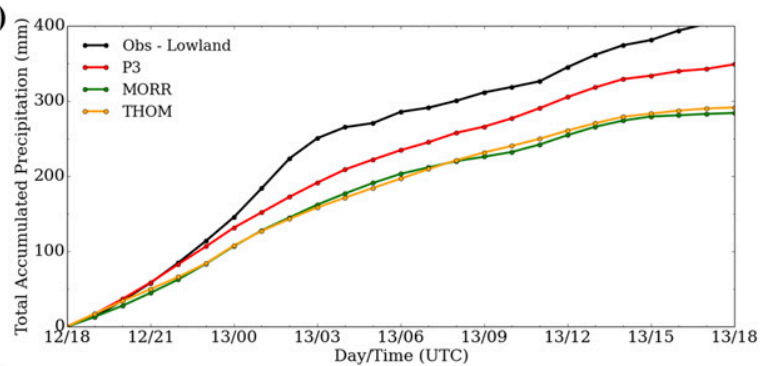

b)

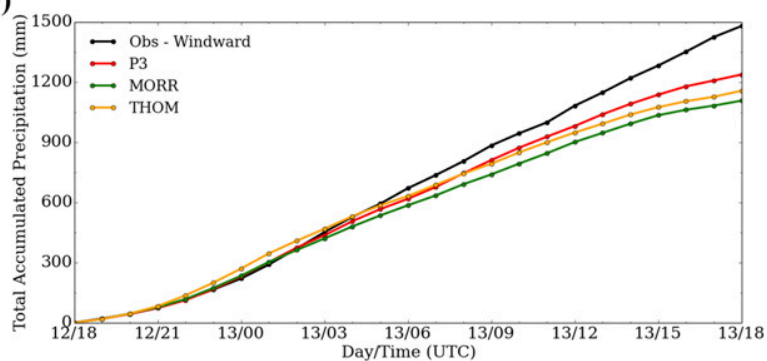

FIG. 4. (a) Lowland and (b) windward observed precipitation time series constructed from site locations denoted in white and blue, respectively, in Fig. 1a. Model precipitation time series constructed using bilinear interpolation of 4 nearest model grid points to site location for P3, MORR, and THOM schemes.

angle shows a broad area of reflectivity exceeding $25 \mathrm{~dB} Z$ across the region with the strongest reflectivity of 35-40 dBZ just upstream of the windward slopes in the blocked flow regime (Fig. 6a). Southerly wind flow at $10-\mathrm{m}$ is measured by the automated surface observation stations (ASOS) near the coast (Fig. 6a). The NPOL RHI scan at the $54^{\circ}$ azimuthal angle along the direction of the mean low-level $(\sim 900-700 \mathrm{hPa})$ wind flow has an enhanced layer of outbound velocities peaking near $30 \mathrm{~m} \mathrm{~s}^{-1}$ just below $2 \mathrm{~km}$ above mean sea level (MSL) associated with a low-level jet and shear layer $\left(\sim 20 \mathrm{~m} \mathrm{~s}^{-1} \mathrm{~km}^{-1}\right)$ over the lowland region (Fig. 6b).

Reflectivity along the NPOL RHI scan exceed $40 \mathrm{dBZ}$ around $2 \mathrm{~km}$ MSL associated with a melting layer (Fig. 6c). Within the warm layer, the highest $\mathrm{dB} Z$ is over the lowlands $(<25 \mathrm{~km}$ range along NPOL scan) with the blocked flow, while shallower precipitation features were downwind of the barrier crest $(\sim 45 \mathrm{~km}$ into the scan). There are some streaks of reflectivity (30-40 dBZ) from the surface to the bright band near $2 \mathrm{~km}$ MSL over the lowlands, which suggests significant precipitation growth within and above the melting layer. The narrow layer of ZDR $<0 \mathrm{~dB}$ directly above the slight depression in the melting layer where ZDR exceeds $2 \mathrm{~dB}$ across the lowland region (0 to $20 \mathrm{~km}$ along the RHI scan in Fig. 6d) suggests the presence of denser, faster falling rimed particles at this location (Kumjian et al. 2016). Below the melting level, ZDR $>1 \mathrm{~dB}$ is dominant across the lowland region, indicative of larger raindrops $>1 \mathrm{~mm}$ in diameter originating from the melting layer (Gorgucci et al. 2002). Furthermore, EDR values exceed the moderate turbulence threshold (EDR $>0.10 \mathrm{~m}^{2 / 3} \mathrm{~s}^{-1}$; ICAO 2010) within the upper and lower boundaries of the strong lowlevel jet from about 0 to $25 \mathrm{~km}$ along the RHI scan (Fig. 6e). The turbulent layer around $2 \mathrm{~km}$ MSL may be promoting additional precipitation growth via cold rain processes within the melting layer, while the turbulent layer below $1.5 \mathrm{~km}$ MSL can promote warm rain growth. Hydrometeor classification retrievals provide further evidence of rimed particles as identified by high and low density graupel within the melting layer, particularly over the lowland region of the scan (Fig. 6f).

The BMP schemes capture the general pattern in the observed horizontal reflectivity over the Olympic Peninsula with noticeable enhancements occurring over the lowlands

TABLE 3. Absolute differences $(\mathrm{mm})$ between model and observed total accumulated precipitation at each lowland and windward site location in Fig. 1a for the 21- and 30-h forecast period of 12-13 Nov and 16-17 Nov, respectively. All sites is the average of the sites in each region. Parentheses indicate negative differences.

\begin{tabular}{|c|c|c|c|c|c|c|c|}
\hline \multirow[b]{2}{*}{ Region } & \multirow[b]{2}{*}{ Site } & \multicolumn{3}{|c|}{ 12-13 Nov 2015} & \multicolumn{3}{|c|}{ 16-17 Nov 2015} \\
\hline & & P3 & MORR & THOM & $\mathrm{P} 3$ & MORR & THOM \\
\hline \multirow[t]{5}{*}{ Lowland } & $\mathrm{N} 28$ & 5.22 & $(26.82)$ & $(23.11)$ & 2.57 & $(27.70)$ & $(9.26)$ \\
\hline & N35 & (14.68) & $(16.74)$ & $(20.52)$ & $(17.40)$ & $(21.22)$ & (17.93) \\
\hline & N41 & $(24.19)$ & (33.64) & $(33.38)$ & $(2.47)$ & $(11.95)$ & $(5.49)$ \\
\hline & N45 & $(13.45)$ & $(24.17)$ & $(20.67)$ & $(56.82)$ & $(73.24)$ & (64.11) \\
\hline & All sites & (11.78) & $(25.34)$ & $(24.42)$ & $(18.53)$ & (33.53) & $(24.20)$ \\
\hline \multirow[t]{7}{*}{ Windward } & N02 & (18.89) & $(0.34)$ & $(29.38)$ & 16.37 & 12.29 & 17.40 \\
\hline & N04 & $(26.29)$ & $(36.28)$ & $(24.24)$ & $(26.70)$ & $(63.93)$ & $(59.01)$ \\
\hline & $\mathrm{N} 29$ & $(1.90)$ & $(39.41)$ & $(23.59)$ & $(39.22)$ & $(55.43)$ & $(53.04)$ \\
\hline & $\mathrm{N} 42$ & $(70.37)$ & $(72.86)$ & $(62.76)$ & $(42.46)$ & (46.12) & (45.42) \\
\hline & $\mathrm{N} 43$ & $(36.41)$ & $(70.05)$ & $(63.52)$ & $(38.80)$ & $(68.39)$ & $(68.31)$ \\
\hline & $\mathrm{P} 10$ & 2.62 & $(35.10)$ & $(10.24)$ & 9.34 & $(22.65)$ & (4.63) \\
\hline & All sites & $(25.21)$ & $(42.34)$ & $(35.62)$ & $(20.25)$ & $(40.71)$ & $(35.50)$ \\
\hline
\end{tabular}


TABLE 4. Absolute differences ( $\mathrm{mm}$ ) between model and observed total accumulated precipitation for the lowland sites during the blocked flow period (1800 UTC 12 Nov -0200 UTC 13 Nov) and the windward sites during the unblocked flow period (02001500 UTC 13 Nov). Figure 1a shows location of lowland and windward sites. All sites is the average of the sites in each region and flow regime. Parentheses indicate negative differences.

\begin{tabular}{clrrr}
\hline \hline Region/flow & Site & P3 & MORR & THOM \\
\hline Lowland/blocked & N28 & 3.52 & $(9.06)$ & $(9.02)$ \\
& N35 & $(22.60)$ & $(22.75)$ & $(25.29)$ \\
& N41 & $(16.27)$ & $(26.30)$ & $(25.21)$ \\
& N45 & $(16.11)$ & $(20.75)$ & $(21.26)$ \\
& All sites & $(12.87)$ & $(19.72)$ & $(20.20)$ \\
Windward/unblocked & N02 & $(14.60)$ & $(7.55)$ & $(23.63)$ \\
& N04 & $(24.02)$ & $(30.78)$ & $(30.62)$ \\
& N29 & $(17.98)$ & $(53.99)$ & $(41.00)$ \\
& N42 & $(53.05)$ & $(60.83)$ & $(66.49)$ \\
& N43 & $(43.66)$ & $(63.92)$ & $(78.31)$ \\
& P10 & $(2.21)$ & $(29.09)$ & $(11.81)$ \\
& All sites & $(25.92)$ & $(41.03)$ & $(41.98)$ \\
\hline
\end{tabular}

(Fig. 7a, only P3 shown). Model cross sections along the NPOL RHI $54^{\circ}$ azimuthal reveal similar structures in the simulated radial velocity and low-level jet between all the BMPs and NPOL observations (Fig. 7b; only P3 shown), with the maximum velocities in the model being too fast by up to $3 \mathrm{~m} \mathrm{~s}^{-1}$ within the core of the jet. The BMPs also depict the observed enhancement in reflectivity $(>35 \mathrm{dBZ}$ ) extending from the melting layer to surface over the lowlands, but the enhancement is concentrated closer to the terrain from about $20-40 \mathrm{~km}$ along the cross section in the model (Figs. 7c,e,g). Stable conditions are predicted along the cross section as shown by a strong increase in $\theta_{e}^{*}$ with height in the lowest $3 \mathrm{~km}$ MSL, which permits only shallow plumes of vertical motions exceeding $1 \mathrm{~m} \mathrm{~s}^{-1}$.

We also compare simulated hydrometeor mass contents between the microphysical schemes with the understanding that the representation of ice within the $\mathrm{P} 3$ scheme is completely different than MORR and THOM. For example, all ice mass is contained within a total ice mass category in P3, while the MORR and THOM schemes contain separate ice, snow, and graupel categories. To allow for a fairer comparison between the schemes, we sum the separate frozen hydrometeor categories to calculate a total ice mass for the MORR and THOM schemes. Note also that rime mass is a subset of the total ice category in $\mathrm{P} 3$, while rimed particles are represented by the separate graupel category in MORR and THOM. In the cross sections, total ice mass generally exceeds $0.4 \mathrm{~g} \mathrm{~m}^{-3}$ over a $1-2 \mathrm{~km}$ layer above the freezing level within all schemes (Figs. 7d,f,h). However, MORR predicts nearly all snow within this layer as graupel mass is well below $0.1 \mathrm{~g} \mathrm{~m}^{-3}$ (Fig. 7f), while graupel exceeds $0.1 \mathrm{~g} \mathrm{~m}^{-3}$ over a portion of the lowlands within the
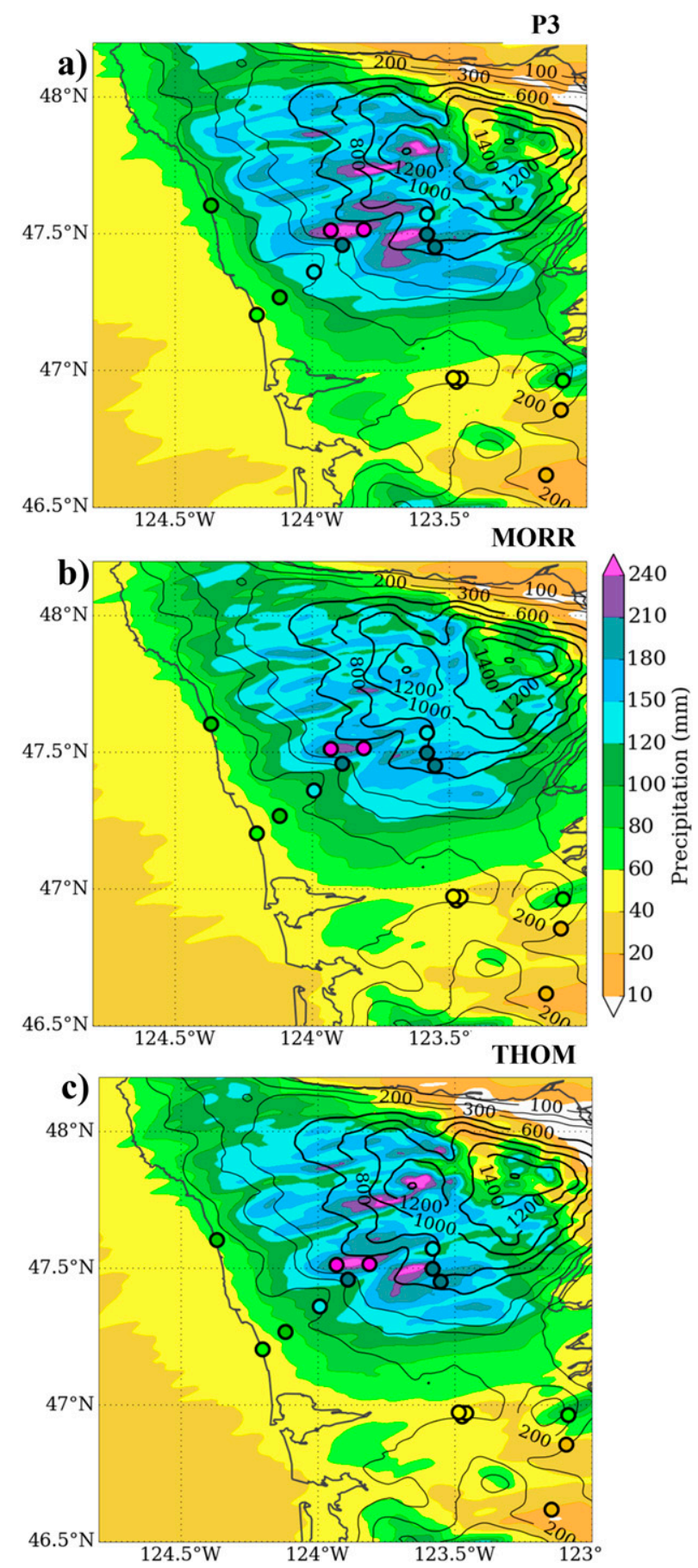

FIG. 5. Total accumulated precipitation (shaded) from (a) P3, (b) MORR, and (c) THOM during the 21-h forecast beginning 1800 UTC 12 Nov. Observed totals during same forecast period are shown at each site (circles) where quality-assured precipitation measurements were available. Refer to Fig. 1a for further details on site locations.

THOM scheme (Fig. 7h). Graupel fractions (graupel mass/total ice mass) remain below 0.2 and 0.1 in the corresponding THOM and MORR cross sections (not shown). P3 simulates a well-defined layer of partially 
a)

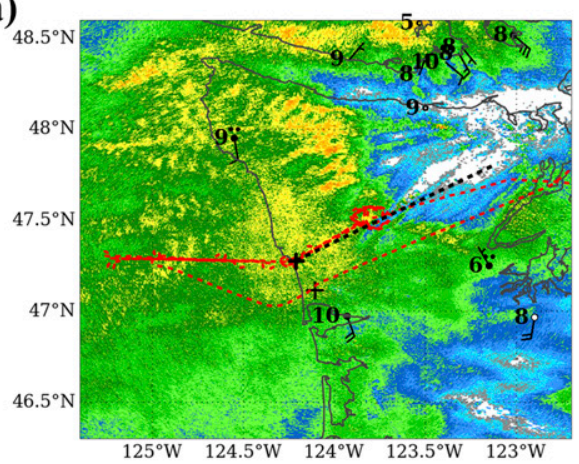

c)

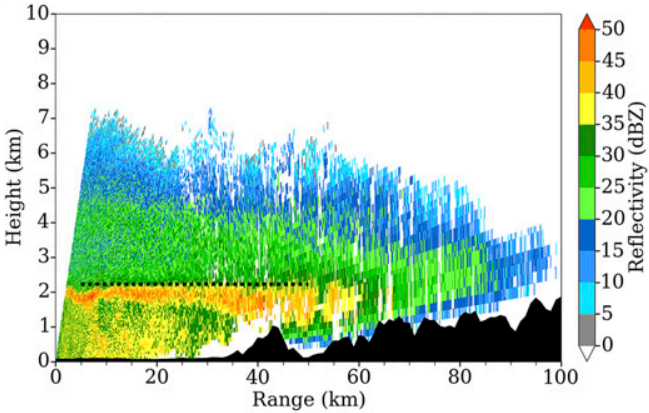

e)

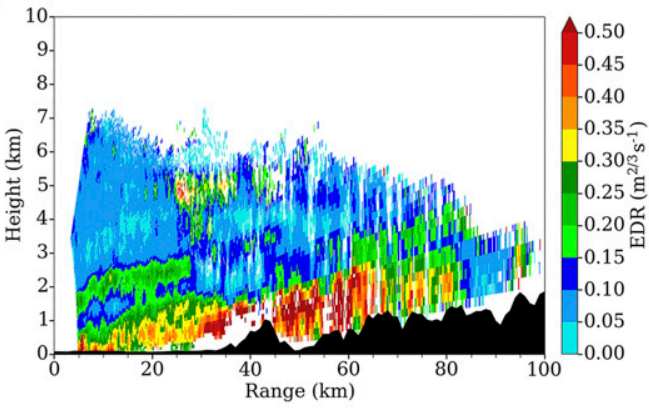

b)

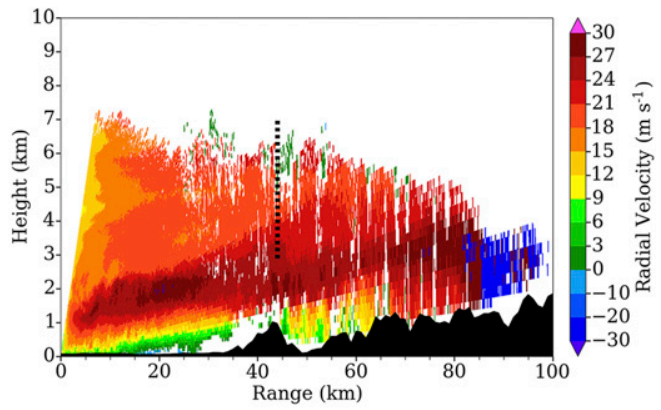

d)

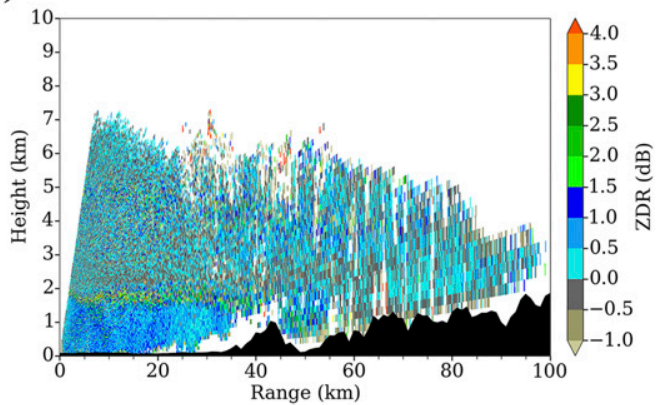

f)

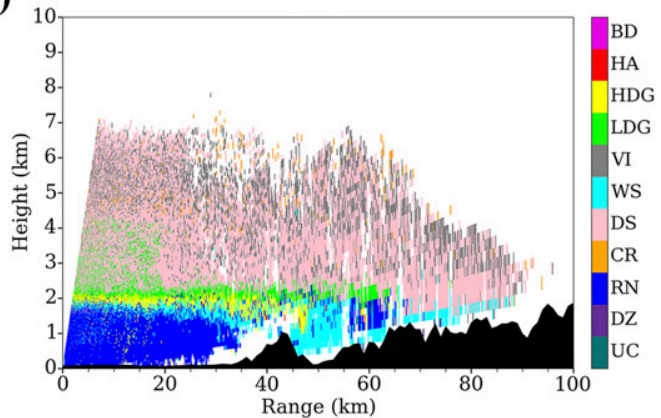

FIG. 6. (a) Radar reflectivity from the NPOL and NEXRAD (KATX, KLGX, KRTX) $0.5^{\circ}$ elevation scans (shaded in $\mathrm{dBZ}$ ) at approximately 2100 UTC 12 Nov 2015. The 2-m temperature $\left({ }^{\circ} \mathrm{C}\right)$ and 10 -m wind speed $(1$ full barb $=10 \mathrm{kt}$ ) at 2100 UTC from ASOS stations are also shown. Aircraft track highlighted in dashed red with the spiral indicated by circular patterns over windward slopes and NPOL RHI $54^{\circ}$ azimuthal scan shown in dashed black. Radar variables from the NPOL RHI $54^{\circ}$ scan at 2132 UTC 12 Nov 2015: (b) radial velocity (aliased at the 80-100 km range), (c) reflectivity, (d) ZDR, (e) EDR, and (f) hydrometeor classification. Location of aircraft spiral denoted by vertical dashed line in (b) and approximate location of $0^{\circ} \mathrm{C}$ level from CSU sounding shown by horizontal dashed line in (c). Hydrometeor classifications are defined as (from bottom to top) $\mathrm{UC}=$ unclassified, $\mathrm{DZ}=$ drizzle, $\mathrm{RN}=$ rain, $\mathrm{CR}=$ ice crystals, $\mathrm{DS}=$ dry snow, $\mathrm{WS}=$ wet snow, $\mathrm{VI}=$ vertical ice, $\mathrm{LDG}=$ low-density graupel, $\mathrm{HDG}=$ high-density graupel, $\mathrm{HA}=$ hail, and $\mathrm{BD}=$ big drops/melting hail.

rimed particles with mass $>0.2 \mathrm{~g} \mathrm{~m}^{-3}$ and rime fraction (rime mass/total ice mass) $>0.3$ just above the freezing level from the coast to high terrain (Fig. 7d; rime fraction not shown), which resembles the narrow layer of riming directly above the bright band in the NPOL observations. The areas of enhanced total ice and rime mass along the P3 cross section are associated some larger rain mass of $0.5-0.7 \mathrm{~g} \mathrm{~m}^{-3}$ below the melting layer, while overall less rain mass $\left(<0.5 \mathrm{~g} \mathrm{~m}^{-3}\right)$ is predicted by the
MORR and THOM schemes. The more efficient ice and rime production and associated melting processes in the P3 scheme lead to generally stronger rain mass growth within the melting layer, which promotes larger precipitation rates and accumulation totals across the lowland region during the stable, blocked flow period (i.e., Fig. 4a).

The ascent profile of the UND aircraft between 1940 and 2010 UTC 12 November (red circle in Fig. 6a) provide additional measurements for assessing the BMPs 
P3
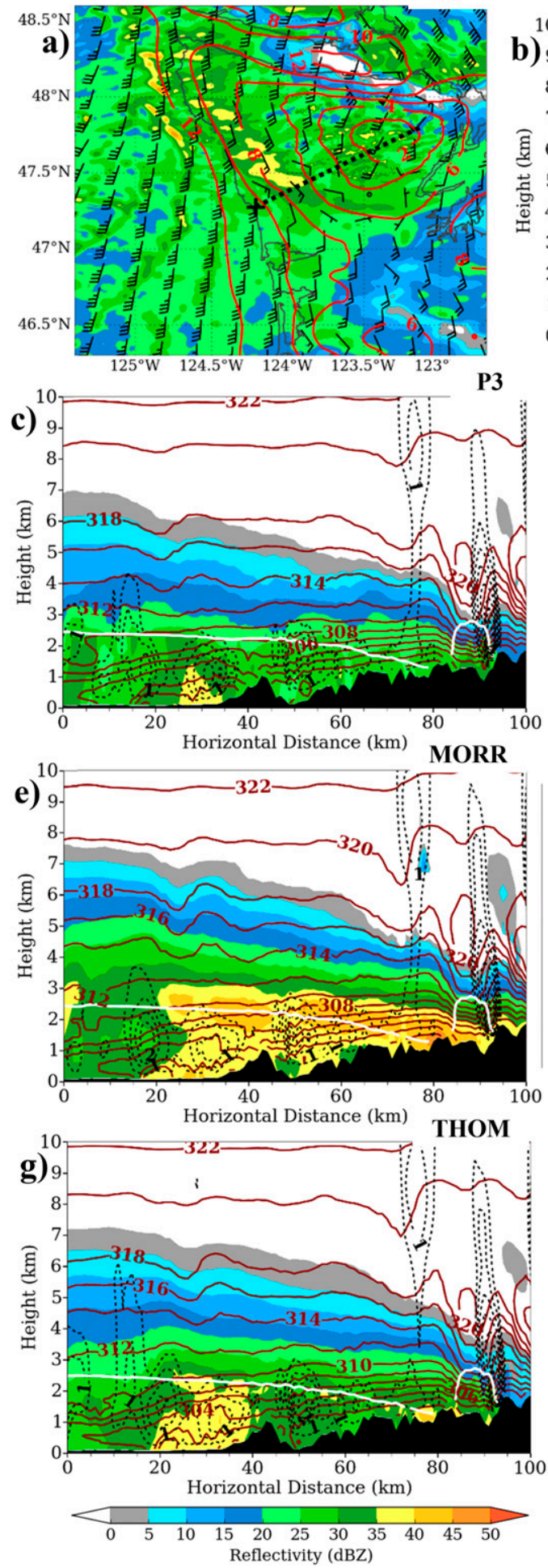

P3
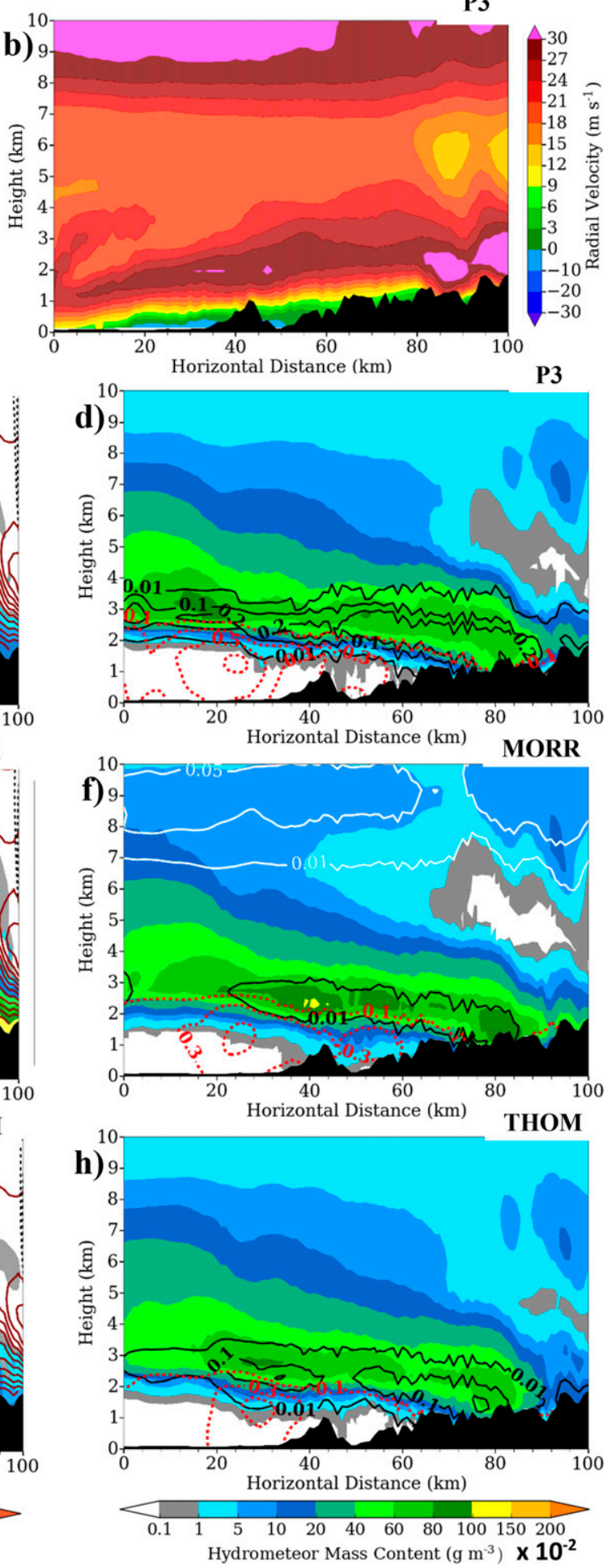

FIG. 7. (a) WRF P3 reflectivity (shaded) at 2100 UTC 12 Nov 2015 from the lowest model vertical level, along with the predicted $2-\mathrm{m}$ temperature (red, contoured every $2^{\circ} \mathrm{C}$ ) and $10-\mathrm{m}$ wind speed $(1$ full barb $=10 \mathrm{kt})$. NPOL location indicated by black cross, with approximate path of NPOL $54^{\circ}$ RHI scan in dashed black. Cross sections along NPOL RHI $54^{\circ}$ azimuthal scan in Fig. 6. (b) Simulated P3 radial velocity and (c) reflectivity (shaded in $\mathrm{dBZ}$ ), $\theta_{e}^{*}$ (solid maroon, contoured every $2 \mathrm{~K}$ ), and vertical velocity (dashed black, contoured every $0.5 \mathrm{~m} \mathrm{~s}^{-1}$ ) at 2130 UTC 12 Nov. Solid white line represents the freezing level at 273 K. (d) Simulated P3 hydrometeor mass 
during the blocked flow period. All BMPs provide a realistic representation of the total ice content during this period as illustrated by the comparison to the observed IWC from the Nevzorov probe (Figs. 8a-c). However, P3 slightly overestimates the total ice content when compared to the observations, which could be aiding the production of rime mass within the scheme (Fig. 8a), while MORR predicts too rapid of increases in total ice content, particularly below about $4.5 \mathrm{~km}$ MSL (Fig. 8b). All schemes generally overestimate the total ice content below about $4 \mathrm{~km}$ MSL, with MORR predicting amounts approaching $1 \mathrm{~g} \mathrm{~m}^{-3}$ near $2 \mathrm{~km} \mathrm{MSL}$ (no aircraft measurements available below $3 \mathrm{~km}$ MSL). Some liquid water was also observed by the King probe as LWC peaks at approximately $0.07 \mathrm{~g} \mathrm{~m}^{-3}$ near the base of the profile. $\mathrm{P} 3$ and THOM predict rather similar cloud water with amounts close to the King measurements at $3 \mathrm{~km}$, while MORR simulates the largest cloud water among the schemes with amounts near $0.1 \mathrm{~g} \mathrm{~m}^{-3}$ at the base of the aircraft profile. The limited uptake of cloud water for producing graupel promotes the larger amounts in MORR. Conversely, rime and graupel production in P3 and THOM helps to limit cloud water within the schemes, with the most efficient uptake of cloud water occurring in P3, which promotes rime mass of about $0.1 \mathrm{~g} \mathrm{~m}^{-3}$ at the base of the aircraft profile.

For evaluating particle properties within the BMPs, we use the aircraft $D_{m}$ calculated from $M_{1+b_{m}} / M_{b_{m}}$ with $M_{b_{m}}$ representing the number of moments. For the aircraft $D_{m}$, the $b_{m}$ of 2 corresponds to the nonspherical snow particles (Locatelli and Hobbs 1974) that were dominant in the particle imagery during the ascent profile. For the model calculated $D_{m}$ at 2000 UTC 12 November in the proximity of the aircraft profile, we used $b_{m}$ assumed within each BMP scheme (Table 2). A depositional snow growth layer with temperatures around $-15^{\circ} \mathrm{C}$ and increases in aircraft $D_{m}$, occurs between 4 and $4.5 \mathrm{~km}$ MSL (Fig. 8d). The larger $D_{m}$ in this layer from the MORR simulation is tied to the unrealistic assumption of spherical snow particles and set $b_{m}$ of 3 within the scheme. Conversely, the nonspherical parameterization in THOM produces too small of $D_{m}$ as the single-moment scheme relies heavily on predicting snow moments based on the rather linear decreasing temperature profile from the Field et al. (2005) dataset. The nonspherical double-moment approach valid for the single-ice category in $\mathrm{P} 3$ shows a slight improvement in $D_{m}$ within the deposition layer, even though an inherent bias may be impacting the $D_{m}$ comparison against aircraft as the single-ice category in P3 can include small ice particles down to $10 \mu \mathrm{m}$ in size, while particles less than $100 \mu \mathrm{m}$ were neglected in the aircraft $D_{m}$ profile. Below $4 \mathrm{~km}$ MSL, active aggregation of the spherical snow particles combined with the lack of rimed snow and graupel production promotes too large of $D_{m}$ exceeding $3 \mathrm{~mm}$ in the MORR simulation, which influences the large reflectivity values over the higher terrain (i.e., Fig. 7e). For the P3 scheme, smaller precipitating ice particles associated with rimed ice below $4 \mathrm{~km}$ MSL leads to the realistic fit to the observations.

We also compare mass-weighted mean terminal fall speeds (Fig. 8e) and particle densities ( $\rho_{\mathrm{pi}}$; Fig. $\left.8 \mathrm{f}\right)$ between the BMPs, although aircraft estimates are unavailable for these parameters. For the MORR and THOM schemes, we calculate values representative of a bulk precipitating ice category based on the weighted fractions of snow and graupel mixing ratios at each model grid point for a more direct comparison to P3. For all schemes, the fall speeds steadily increase to over $1 \mathrm{~m} \mathrm{~s}^{-1}$ down to about $3 \mathrm{~km}$ in height (Fig. 8e). Below this height, precipitating ice fall speeds increase to about $2.5 \mathrm{~m} \mathrm{~s}^{-1}$ at $2 \mathrm{~km} \mathrm{MSL}$ in the $\mathrm{P} 3$ simulation as the particles become partially rimed, which leads to an increase in $\rho_{\mathrm{pi}}$ to over $250 \mathrm{~kg} \mathrm{~m}^{-3}$. Not surprisingly, terminal fall speeds show a minimal increase below $3 \mathrm{~km}$ MSL within the MORR scheme as spherical, unrimed snow with a prescribed density of $100 \mathrm{~kg} \mathrm{~m}^{-3}$ is dominant throughout the profile. A slightly larger increase in fall speed to about $1.5 \mathrm{~m} \mathrm{~s}^{-1}$ occurs in the THOM simulation due to larger graupel production than in MORR. Nevertheless, the inverse $\rho_{\mathrm{pi}-}$ diameter relationship in the THOM scheme leads to lower $\rho_{\mathrm{pi}}$ than that prescribed for snow in MORR, while $\rho_{\mathrm{pi}}$ exceeds $200 \mathrm{~kg} \mathrm{~m}^{-3}$ near $2 \mathrm{~km}$ MSL in the P3 simulation (Fig. 8f). The 2D-C particle imagery from just above the melting layer near the NPOL site $(\sim 3 \mathrm{~km}$ MSL at $\sim 2045$ UTC; Fig. 8g) reveals a mixture of particles consisting of larger, rimed aggregates with generally smoothed edges and graupel-like particles with nearspherical shapes, which suggests an underrepresentation

contents including total ice (shaded), rime (solid black, contoured at 0.01, 0.1, 0.2, and $0.4 \mathrm{~g} \mathrm{~m}^{-3}$ ), and rain (dashed red, contoured at $0.1,0.3,0.5,0.7$, and $1.0 \mathrm{~g} \mathrm{~m}^{-3}$ ) averaged from 30-min model output between 2030 and 2130 UTC. (e),(f) and (g),(h) As in (a),(b), but for MORR and THOM simulation, respectively, showing graupel mass (solid black) rather than rime mass as in P3 and nonprecipitating ice mass also shown (white, contoured at 0.001, 0.01, 0.05, and $0.1 \mathrm{~g} \mathrm{~m}^{-3}$ ). Total ice mass in MORR and THOM is sum of ice, snow, and graupel categories. 
a)

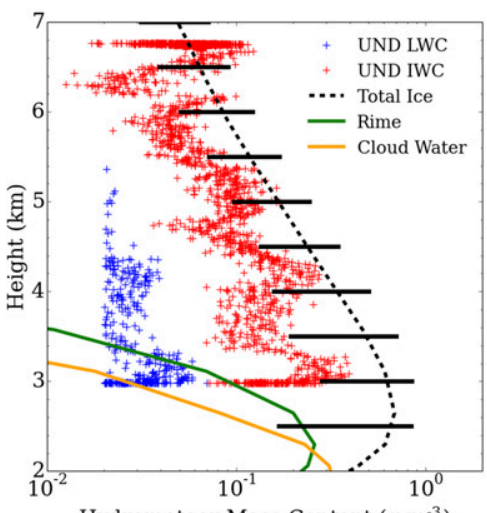

Hydrometeor Mass Content $\left(\mathrm{g} \mathrm{m}^{-3}\right)$

d)

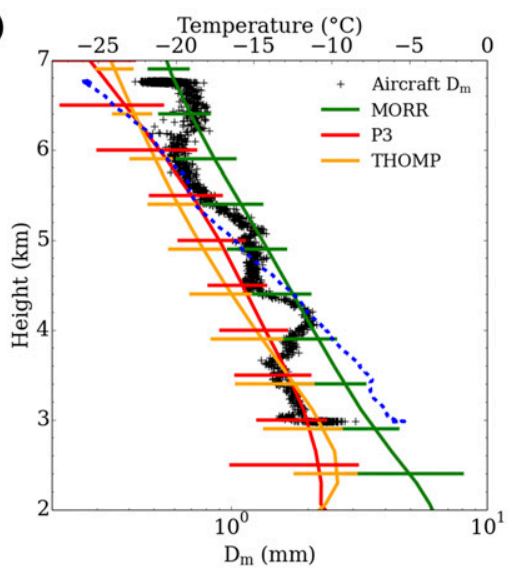

b)

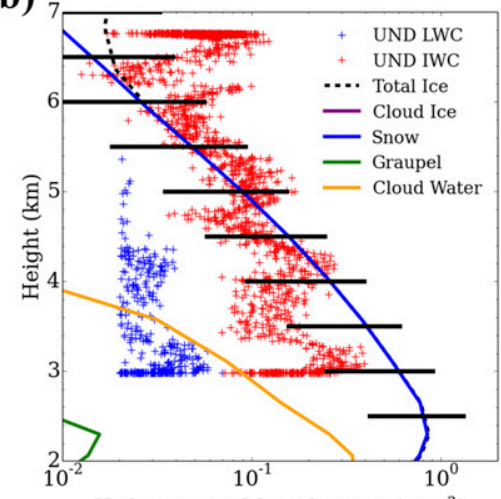

Hydrometeor Mass Content $\left(\mathrm{g} \mathrm{m}^{-3}\right)$

e)

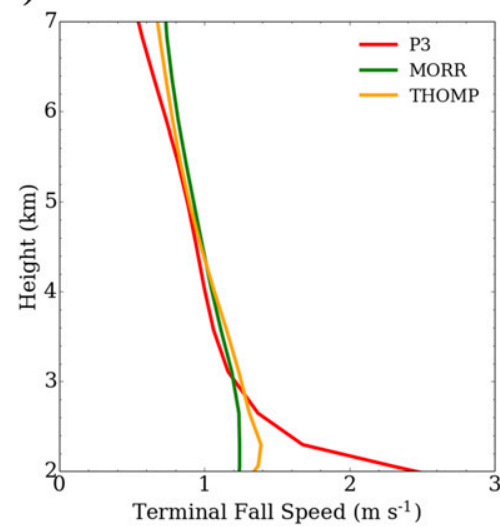

c)

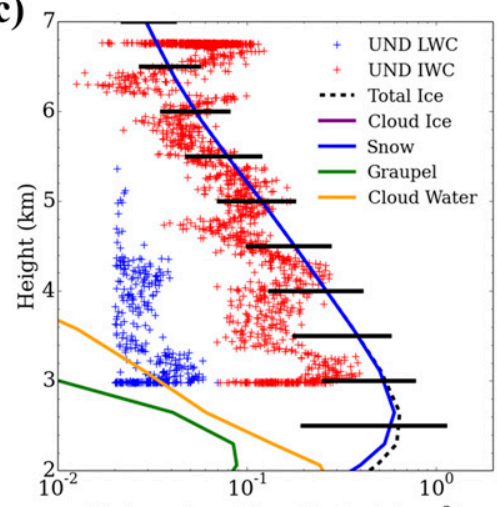

Hydrometeor Mass Content $\left(\mathrm{g} \mathrm{m}^{-3}\right)$

f)

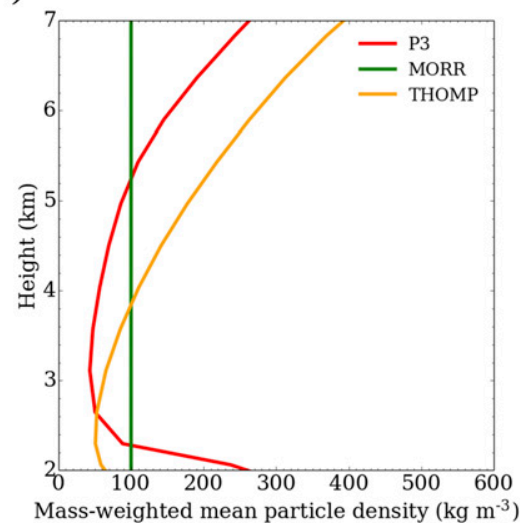

g)
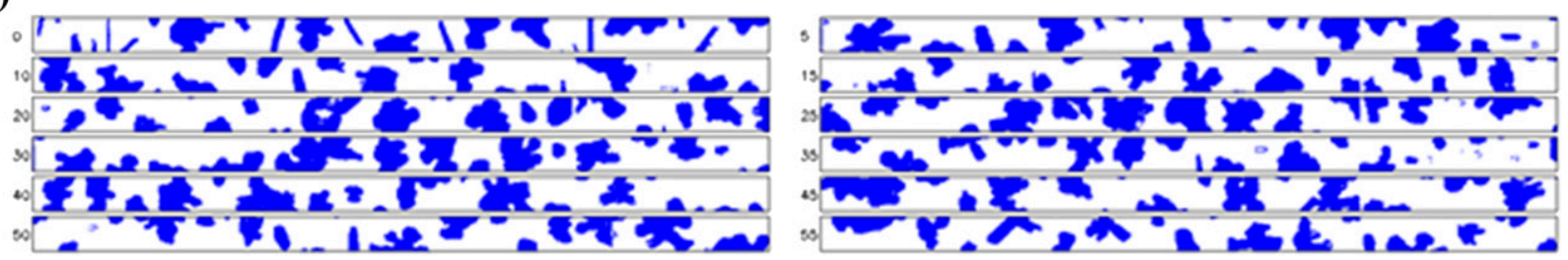

FIG. 8. Mean vertical profiles of hydrometeor content calculated from (a) P3, (b) MORR, and (c) THOM at 2000 UTC 12 Nov 2015 using the nearest 200 grid points to the location of the aircraft spiral. Horizontal bars represent the range of the simulated total ice mass content at $0.5 \mathrm{~km}$ altitude increments. King and Nevzorov probe measurements of cloud liquid water content (blue cross) and total ice content (red cross), respectively, during the ascending spiral between 1940 and 2010 UTC 12 Nov (Fig. 6a). (d) Mean vertical profiles of mass-weighted mean diameter $\left(D_{m}\right)$ calculated from the HVPS measurements during the spiral vs $D_{m}$ calculated from BMP output at same time and location as (a)-(c). Temperature profile measured by aircraft is shown in dashed blue. (e) Simulated massweighted terminal fall speed and (f) mass-weighted mean particle density for precipitating ice species $\left(\rho_{\mathrm{pi}}\right)$ within the schemes (no aircraft estimates available). (g) Particle imagery from 2D-C acquired in 5-s intervals (shown to left of each image) at 1943 UTC and approximately $3 \mathrm{~km}$ in height during aircraft spiral.

of rimed particles in the THOM and MORR simulations with graupel fractions mostly less than 0.1 .

In the later part of the stable period after 0000 UTC 13 November, conditions become partially blocked as $\mathrm{Fr}$ approaches 1 by 0200 UTC as calculated from model output. The NPOL and NEXRAD PPI scans at approximately 0030 UTC 13 November show a distinct increase in reflectivity to more than $35 \mathrm{~dB} Z$ when moving from over the Pacific Ocean to Olympic Peninsula as warm, moist flow associated with a warm frontal passage impacted the region (Fig. 9a). A layer of velocity shear upstream of the high terrain was still apparent in the radial velocity measurements from the NPOL RHI $54^{\circ}$ azimuthal scan (Fig. 9b). Over the lowlands, reflectivity from the NPOL RHI scan depicts a much weaker, narrower bright band at a slightly higher altitude (just above $2 \mathrm{~km}$ MSL) compared to the earlier time (Fig. 9c). An increase in reflectivity within the rain layer is apparent across the 
a)

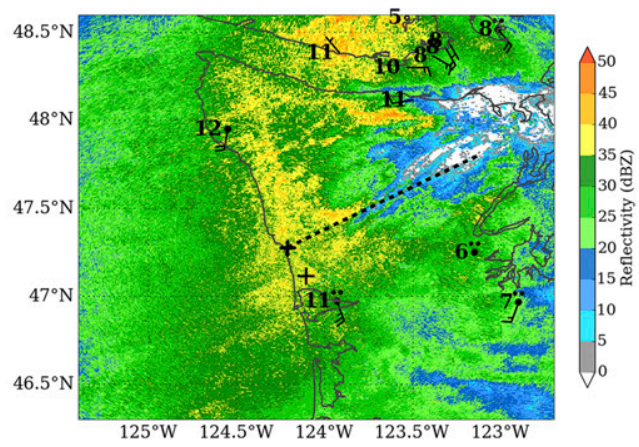

c)

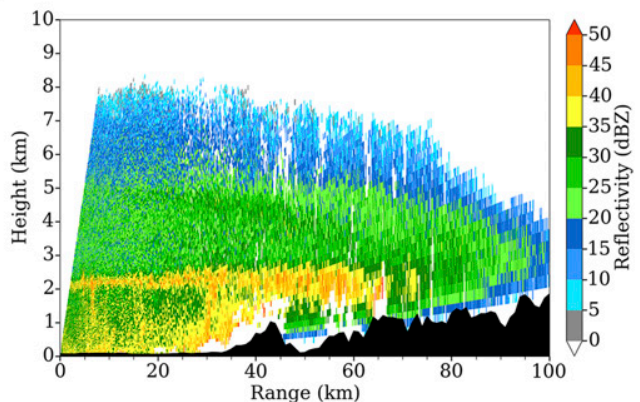

e)

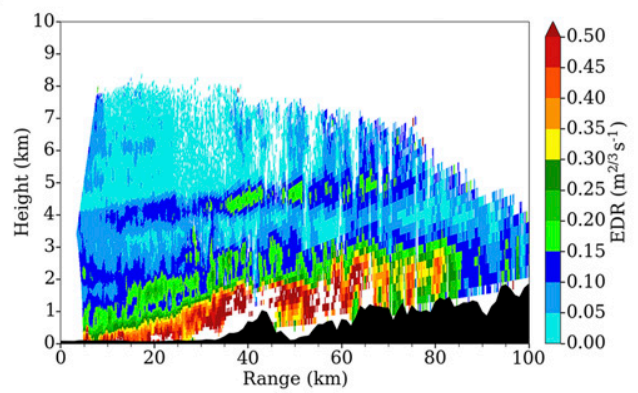

b)

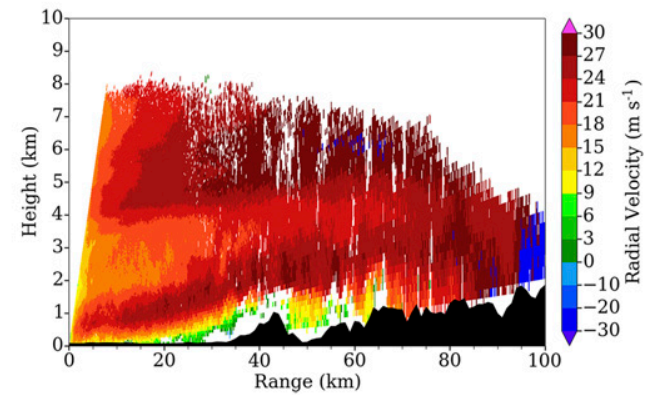

d)

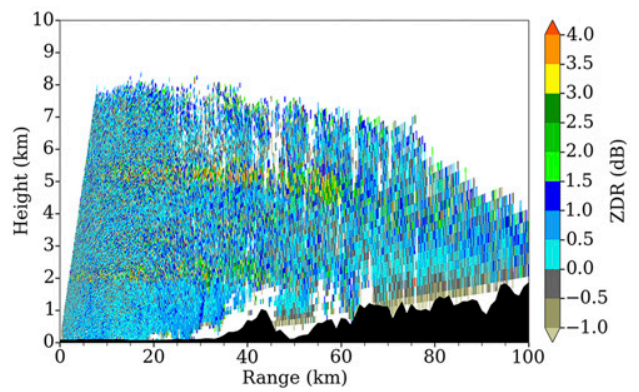

f)

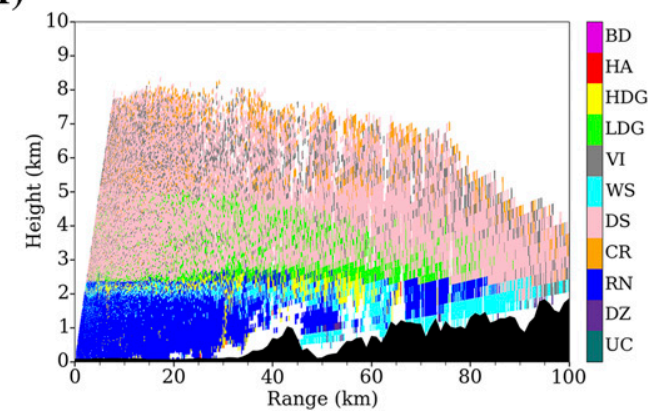

FIG. 9. As in Fig. 6, but (a) at approximately 0030 UTC 13 Nov 2015 for NPOL/NEXRAD PPI scan and (b)-(f) 0116 UTC for NPOL RHI scan. (f) Refer to hydrometeor types listed in Fig. 6 caption.

lowlands as the low-level jet and shear layer descended by more than $0.5 \mathrm{~km}$ into the above freezing environment. The NPOL ZDR is mostly between 0 and $0.5 \mathrm{~dB}$ within the rain layer, which is a decrease from earlier and indicative of smaller drops along the RHI scan (Fig. 9d) as also confirmed in Zagrodnik et al. (2018). Furthermore, the strong enhancement in ZDR around $5 \mathrm{~km}$ MSL is associated with a layer of active depositional growth, which promotes the production of large, falling aggregates that lead to increases in reflectivity and ZDR beneath this layer. The moderate turbulence occurring within the melting layer during the earlier time is now within the rain layer from about 1 to $1.5 \mathrm{~km}$ MSL due to the descent of the low-level jet (Fig. 9e), which suggests that turbulence may be supporting additional accretional rain growth within this layer of enhanced water vapor flux. As expected, the NPOL hydrometeor classifications reveal a deeper layer of rain, along with a melting layer mostly composed of wet snow rather than graupel over the lowlands (Fig. 9f).

For the hydrometeor cross sections along NPOL, the P3 scheme simulates a melting layer with similar characteristics as earlier with rime mass exceeding $0.2 \mathrm{~g} \mathrm{~kg}^{-1}$ in some locations (Fig. 10a). However, rime mass fractions have decreased by about 0.1 across the lowlands due to the increase in total ice mass, which is leading to slower precipitating ice fall velocities (not shown) and subsequent decreases in rain mass below the melting layer compared to the earlier time. The lack of a distinct rain mass growth within the $\mathrm{P} 3$ scheme in the lowest $1.5 \mathrm{~km}$ MSL suggests too weak of warm rain processes when compared to our analysis of the NPOL 
P3
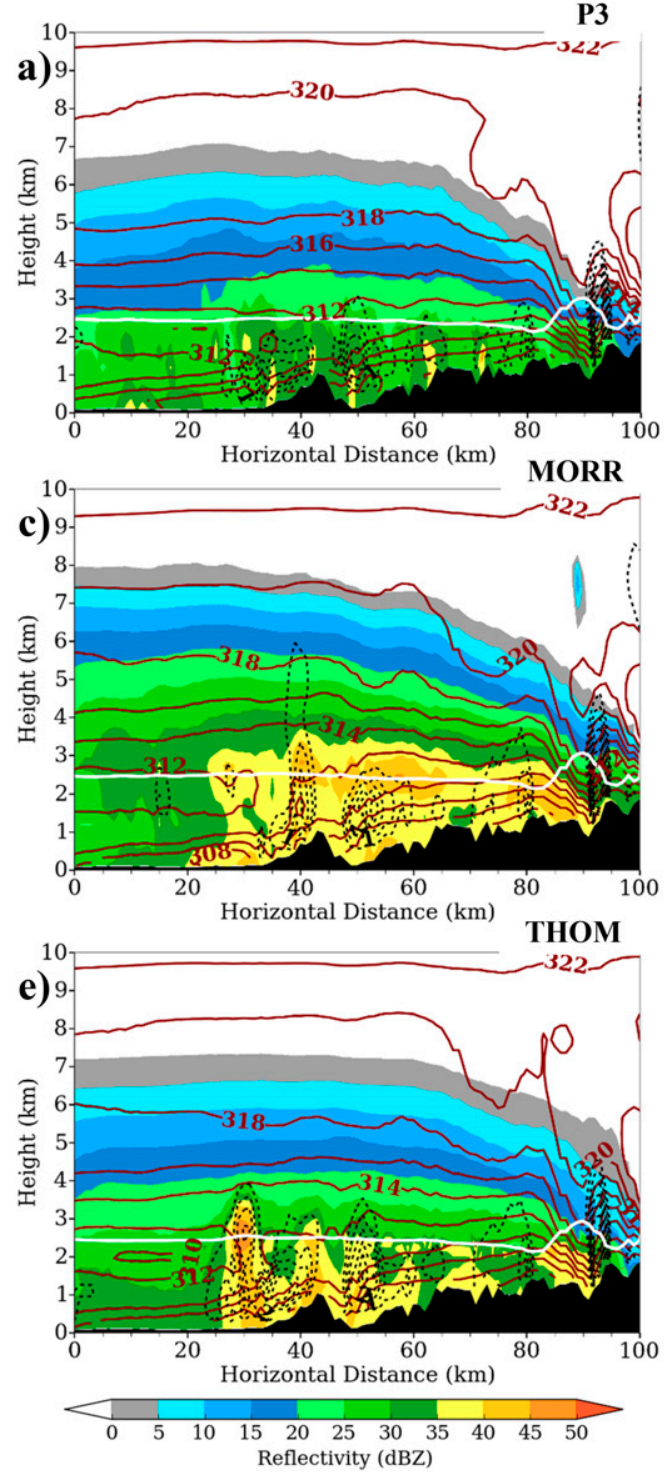

P3
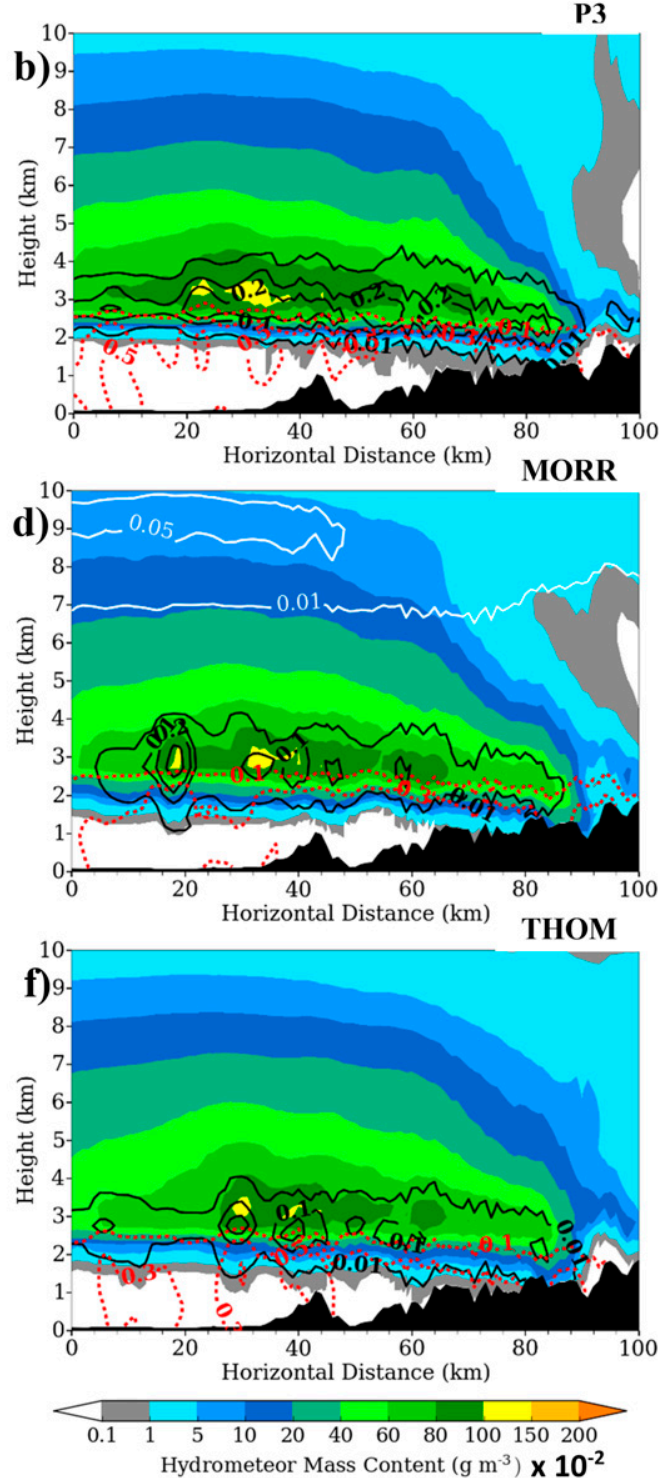

FIG. 10. As in Figs. 7c-h, but (a),(c),(e) at 0100 UTC 13 Nov and (b),(d),(f) averaged from 30-min model output between 0000 and 0200 UTC.

measurements. The MORR (Fig. 10b) and THOM schemes (Fig. 10c) also predict minimal increases in rain mass in the lowest $1 \mathrm{~km}$ MSL, and both simulate small graupel amounts similar to earlier, except for a couple of isolated areas of enhancements.

To summarize this blocked flow period over the lowland region, we compare the WRF BMPs to the ground-based instrumentation at the Fishery site (N28 in Fig. 1a). The enhanced LWC $>2 \mathrm{~g} \mathrm{~m}^{-3}$ in the MRR extends within the melting layer prior to about 0000 UTC 13 November, which illustrates the major contribution of cold rain processes during this strong brightband period (Fig. 11a). After about 0000 UTC, the area of enhanced LWC is mostly confined within the warm layer as the low-level jet descends in height over time to about $1 \mathrm{~km}$ MSL. The low-level turbulent layer observed by NPOL near $1.5 \mathrm{~km}$ MSL is likely providing additional support for the $\mathrm{LWC}>2 \mathrm{~g} \mathrm{~m}^{-3}$ and rain growth processes within the warm layer.

Similar to the MRR during the strong brightband period, the $\mathrm{P} 3$ scheme predicts enhanced LWC near the melting layer height, albeit with less magnitude (LWC > $0.8 \mathrm{~g} \mathrm{~m}^{-3}$ ) than the observed (Fig. 11b). The increase in LWC to over $1 \mathrm{~g} \mathrm{~m}^{-3}$ at around $1 \mathrm{~km} \mathrm{MSL} \mathrm{suggests} \mathrm{rain}$ growth within the warm layer that is mostly tied to the production and melting of frozen hydrometeors aloft (i.e., seeder-feeder process). During the weaker brightband period (after 0000 UTC), the P3 scheme shows 

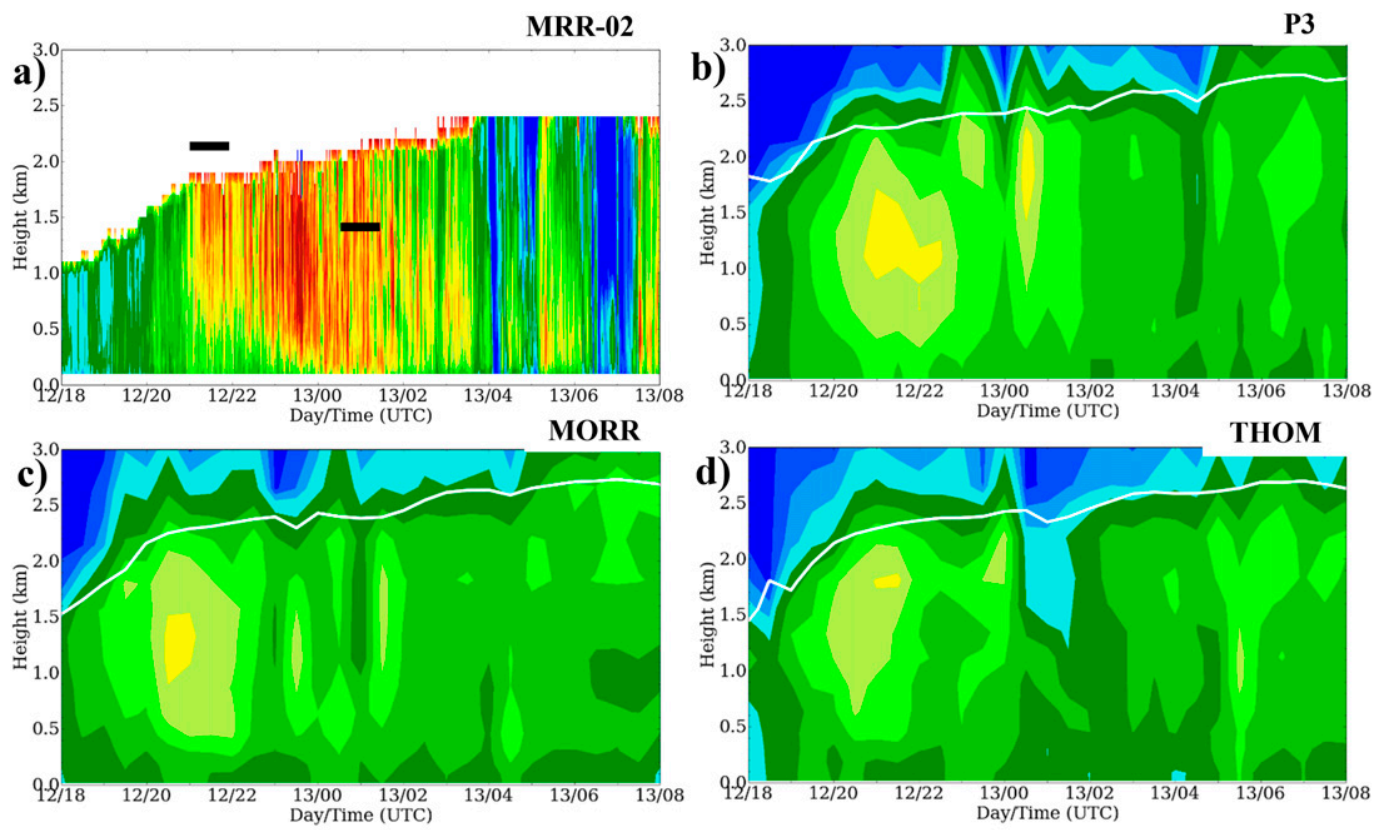

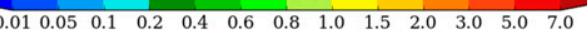

Liquid Water Content $\left(\mathrm{g} \mathrm{m}^{-3}\right)$

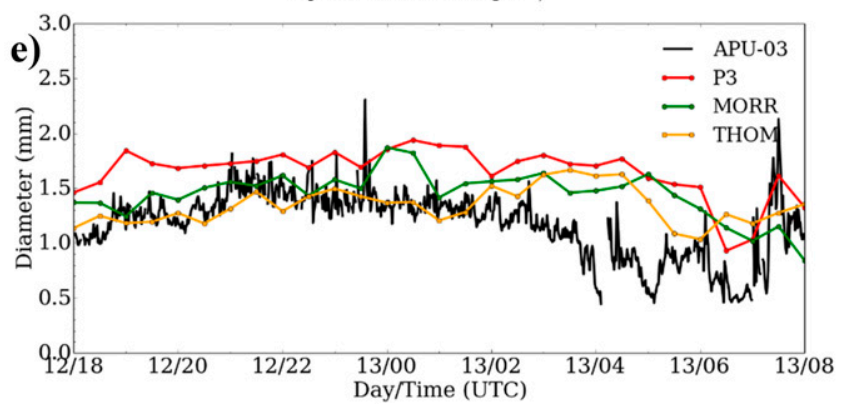

FIG. 11. (a) MRR LWC from 1800 UTC 12 Nov to 0800 UTC 13 Nov at Fishery site (MRR-02). Data unavailable after 0800 UTC 13 Nov due to power outage. Approximate base height of turbulent layer estimated from NPOL EDR is shown by horizontal black bars. Simulated LWC at Fishery site for (b) P3, (c) MORR, and (d) THOM schemes. Freezing level $(273.15 \mathrm{~K})$ denoted by white line. (e) $D_{m}$ from the APU disdrometer at Fishery (APU-03) for same time period as MRR vs simulated rain diameters within the BMPs. Bilinear interpolation of 4 nearest model grid points used to calculate LWC and rain diameters from BMPs at Fishery site.

minimal increases in LWC in the lowest $1.5 \mathrm{~km}$ MSL as shown by the MRR, which suggest too weak of warm rain production in the model. Nevertheless, cold rain production is still apparent during this period, albeit less than earlier, as streaks of LWC $>0.8 \mathrm{~g} \mathrm{~m}^{-3} \mathrm{ex}-$ tend from the melting layer. The MORR (Fig. 11c) and THOM (Fig. 11d) schemes show overall smaller LWC throughout the blocked flow period due primarily to less efficient cold rain production as discussed earlier. Similar to P3 during the weaker bright band, the THOM and MORR schemes show minimal increases in LWC below about $1.5 \mathrm{~km}$ MSL, which indicates a common theme among the BMPs of not adequately resolving the warm rain mass growth during this period. The poorly resolved warm rain processes in the model could be at least partially due to the neglect of a turbulence parameterization within all the BMPs.

For the APU disdrometer at the Fishery site, the $D_{m}$ shows an increase from about 1 to $1.5 \mathrm{~mm}$ between 1800 and 2100 UTC 12 November, which is coincident with the strengthening bright band and observed enhancement of LWC near the melting layer (Fig. 11e). As the area of enhanced LWC descended more into the warm layer after about 0000 UTC 13 November, a decreasing trend in $D_{m}$ is evident with values around $1.2 \mathrm{~mm}$ by $0200 \mathrm{UTC}$. All the BMPs predict little variation in $D_{m}$ when transitioning from the early to later period until about 0500 UTC November 13 as the schemes do not adequately characterize the transitions from more cold to 
a)

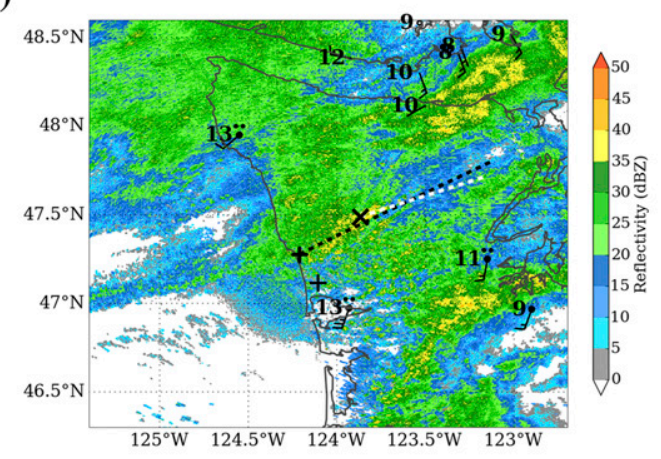

c)

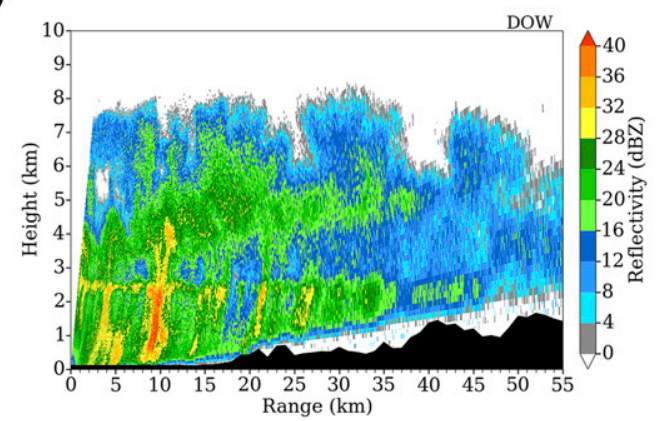

b)

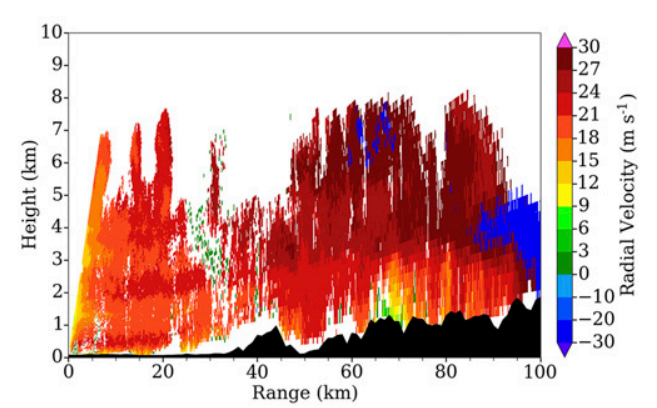

d)

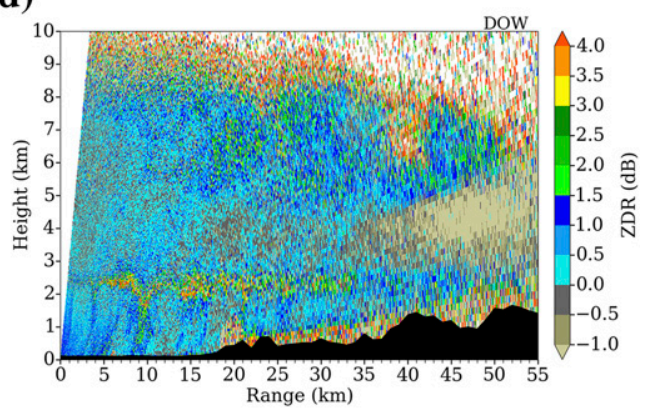

FIG. 12. (a),(b) As in Figs. 6a and 6b, but at approximately 0704 UTC 13 Nov and (a) DOW location denoted by black $\times$ with corresponding $64^{\circ}$ azimuthal scan in dashed white. Radar variables from the DOW RHI $64^{\circ}$ scan at 0704 UTC 13 Nov 2015: (c) reflectivity and (d) ZDR.

warm rain processes. More active cold processes partly contribute to the larger $D_{m}$ in P3 compared to the other BMPs, while warm rain processes are also a major contributing factor, which will be demonstrated from our sensitivity experiments in section 4 . The general overestimation of $D_{m}$ in P3 may be further accentuated by the APU minimum detectable size limit of $0.25 \mathrm{~mm}$ (Tokay et al. 2014).

\section{c. Unblocked flow, less stability over windward slopes}

After $\sim 0200$ UTC 13 November stronger unblocked flow $(\mathrm{Fr}>2)$ over the Olympic barrier resulted in more embedded convection and heavier precipitation over the windward slopes (Fig. 12a). An enhanced layer of outbound velocities exceeding $24 \mathrm{~m} \mathrm{~s}^{-1}$ is dominantly over the windward slopes during this unblocked flow regime (Fig. 12b). The RHI scans from the high-resolution DOW radar deployed near the windward slopes ( $X$ in Fig. 12a) helped diagnose precipitation features during this period. The DOW RHI $64^{\circ}$ azimuthal scan at approximately 0704 UTC highlights vertical plumes of enhanced reflectivity $>28 \mathrm{dBZ}$ extending to over $4 \mathrm{~km} \mathrm{MSL}$ over the windward slope (Fig. 12c), with pronounced fall streaks consisting of large raindrops (ZDR $>1$ ) extending from the strong bright band to the surface (Fig. 12d). At a couple other locations (e.g., $5 \mathrm{~km}$ along the RHI scan), increases in reflectivity in the lowest $1.5 \mathrm{~km}$ MSL reside beneath a relatively weak bright band, with ZDR decreasing to near or below 0 due to the dominant presence of smaller droplets and warm rain processes. The DOW measurements also reveal a depositional growth layer aloft as indicated by the enhanced layer of reflectivity $>24 \mathrm{~dB} Z$ between 4 and $6 \mathrm{~km}$ MSL. The narrow layers of instability aloft in the observed sounding (i.e., Fig. 3b) are likely promoting the development of the depositional growth layer and efficient production of snow particles aloft that descend into the lower level embedded convection for enhancing precipitation growth via the seeder-feeder process. Overall, these features in the DOW measurements illustrate the important role of hybrid processes over the windward slopes.

Similar to the observations, the BMP schemes capture the general shift in the heaviest precipitation and strongest radial velocities (Figs. 13a,b, only P3 shown) to over the windward slopes (Figs. 13a,b, only P3 shown). Our simulations produce deeper plumes of vertical motions exceeding $0.5 \mathrm{~m} \mathrm{~s}^{-1}$ within the embedded convectivelike cells over the windward slopes (Figs. 13c,e,g). These cells are more well-defined in the P3 (Fig. 13c) and MORR simulations (Fig. 13e) compared to THOM (Fig. 13g). All BMPs appear to be poorly representing 

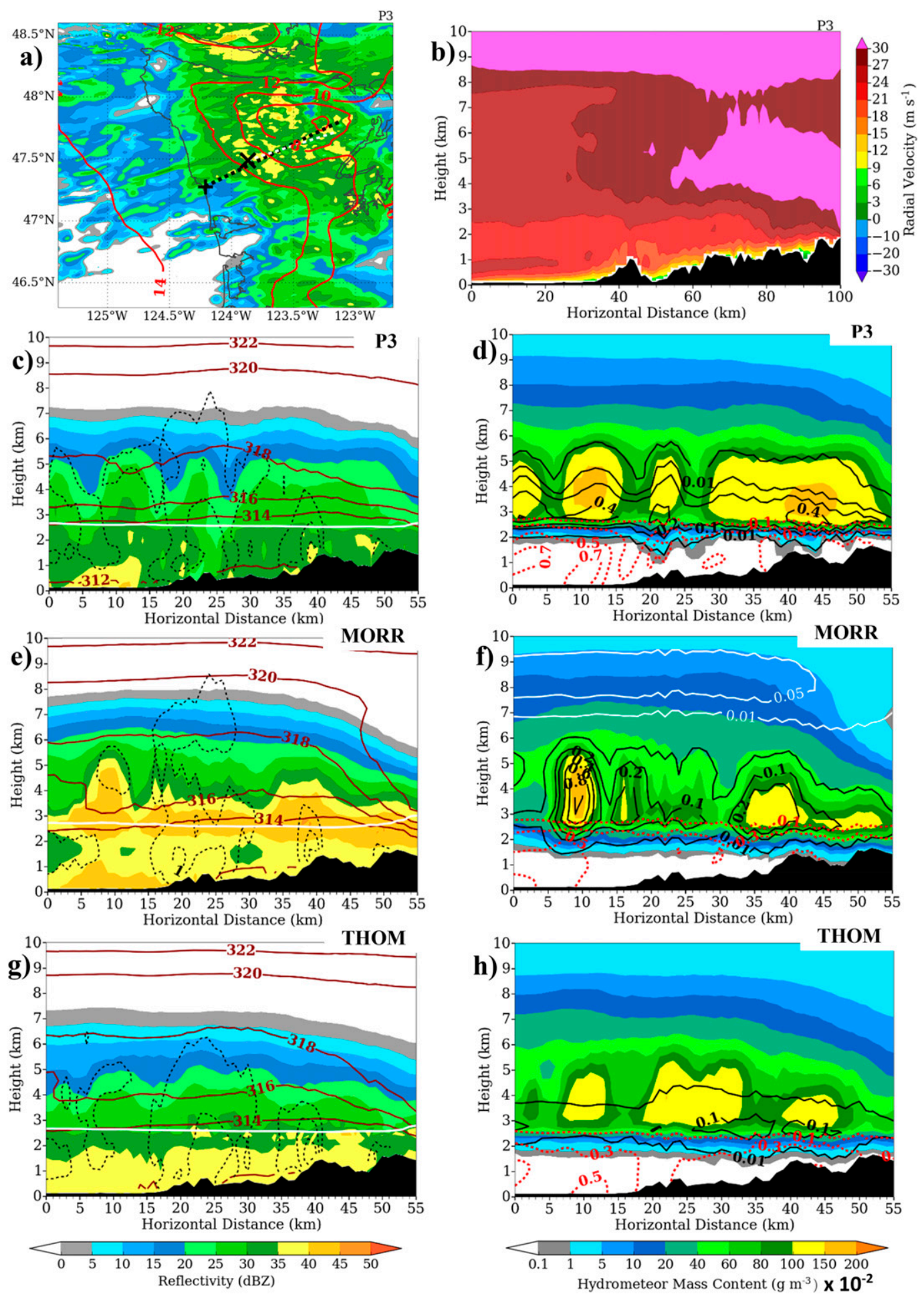

FIG. 13. As in Fig. 7, but at approximately 0730 UTC 13 Nov and along the DOW RHI $64^{\circ}$ azimuthal scan. (a) DOW location denoted by black $\times$ with corresponding $64^{\circ}$ scan in dashed white. 

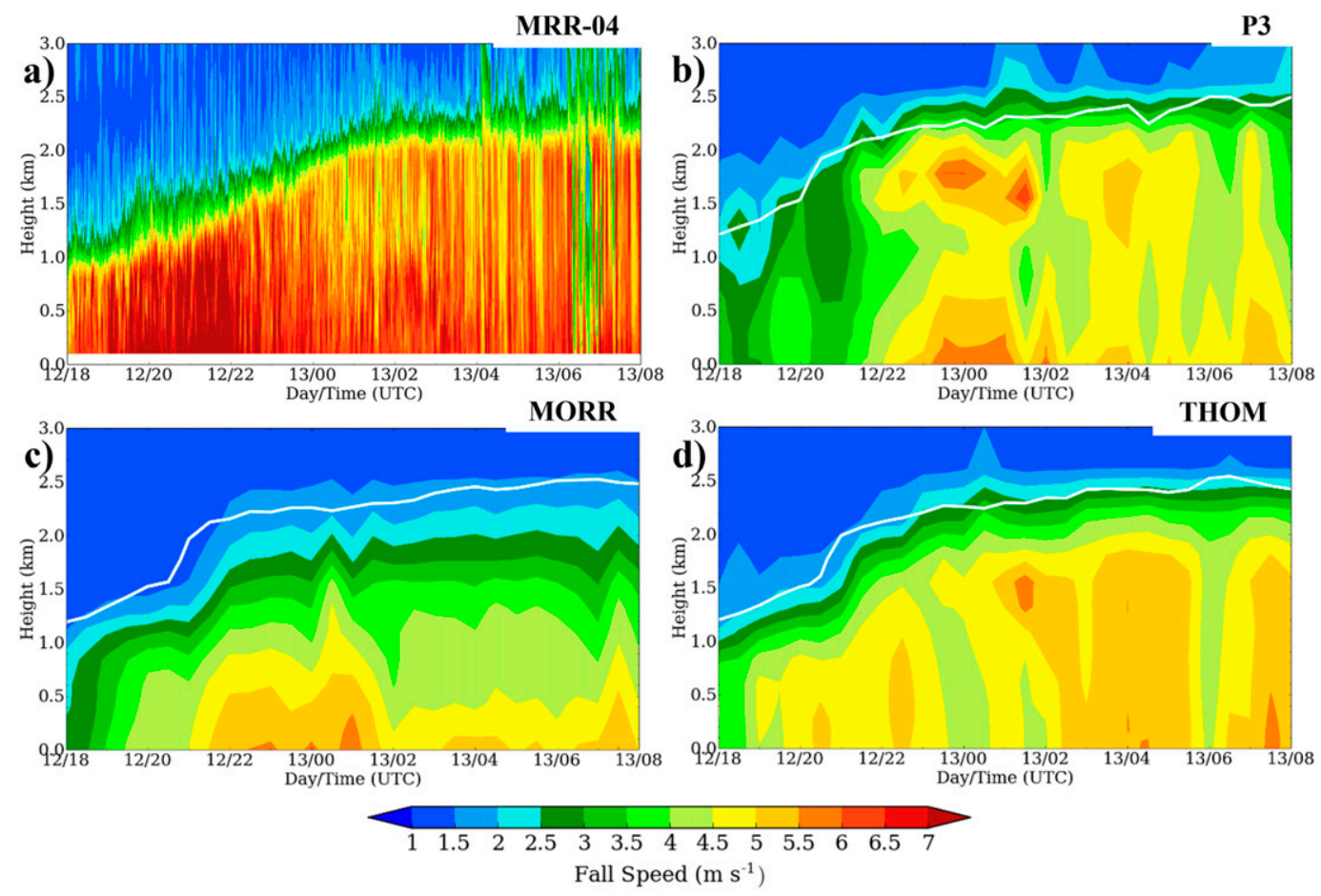

FIG. 14. (a) MRR terminal fall speeds from 1800 UTC 12 Nov to 0800 UTC 13 Nov at Bishop/CRN site (MRR-04). Data unavailable after 0800 UTC 13 Nov due to power outage. Mass-weighted bulk mean terminal fall speeds from (b) P3, (c) MORR, and (d) THOM simulations. Terminal fall speeds are calculated for each precipitation category within the BMPs, which includes snow, graupel, and rain for MORR and THOM and ice and rain for P3. The bulk mean fall speed is calculated based on the average of the fall speeds weighted by the fraction of mass content within each category at each model grid point. Freezing level $(273.15 \mathrm{~K})$ in simulations denoted by white lines in (b)-(d).

the depositional growth layer aloft and lower-level embedded convective cells in the DOW as shown by the less defined reflectivity structures throughout the lowand midlevels of the atmosphere, which may be tied to a WRF resolution issue with resolving the narrow layers of instability aloft (i.e., Fig. 3d) and finescale embedded convection below. For the hydrometeor cross sections, the P3 and MORR schemes predict rime and graupel amounts greater than $0.4 \mathrm{~g} \mathrm{~kg}^{-1}$ within plumes of total ice exceeding $1.5 \mathrm{~g} \mathrm{~kg}^{-1}$ (Figs. 13d,f), but these plumes are more isolated in MORR. Total ice amounts are similar within the plumes in the THOM cross section, but the scheme produces dominantly snow aloft (Fig. 13h). Below the melting layer in the P3 simulation, a significant increase in rain mass to more than $0.7 \mathrm{~g} \mathrm{~kg}^{-1}$ occurs in the lowest $2 \mathrm{~km}$ MSL beneath the convective plume $(\sim 10 \mathrm{~km}$ into the cross section), which indicates that both cold and warm rain growth processes are active (Fig. 13d). The overall strength of these hybrid rain processes are less apparent in the MORR and THOM cross sections (Figs. 13f,g).

The MRR and APU instruments at the Bishop/CRN site (N29 in Fig. 1a) along the windward slopes provide further insight into the BMP performance in this region. The transition from more cold to warm rain processes from the blocked to unblocked flow periods is evident by the decrease in MRR terminal fall speeds below the melting layer (Fig. 14a). For the unblocked flow period after 0200 UTC 13 November, the MRR observes some enhanced fall speeds $>3 \mathrm{~m} \mathrm{~s}^{-1}$ above the melting layer due to the production of rimed, higher density particles within the convective plumes shown in the DOW RHI scans. The P3 scheme underestimates the terminal fall speeds above the melting layer with simulated values $<2.5 \mathrm{~m} \mathrm{~s}^{-1}$ (Fig. 14b), which suggests too little riming within the embedded convective plumes, possibly tied to the WRF resolution issue with the model being unable to adequately resolve the depositional layer and intensity of the embedded convection. Even more drastic underestimation in fall speeds are shown in the MORR (Fig. 14c) and THOM simulations (Fig. 14d) due to minimal riming and graupel production within these schemes. The MORR scheme predicts negligible increases in fall speeds above the melting layer, since the isolated convective plumes in the simulation consist of graupel particles with fall speeds comparable to snow $\left(<2 \mathrm{~m} \mathrm{~s}^{-1}\right)$. Altogether, our 
simulations poorly resolve the seeder-feeder process and the interaction between the enhanced depositional layers and embedded cells at lower levels during the unblocked flow conditions.

All BMPs underpredict fall speeds in the warm layer, which is at least partially attributed to weaker rain accretional growth associated with the poor representation of the seeder-feeder process. The MRR measures increases in fall speeds of $0.5-1 \mathrm{~m} \mathrm{~s}^{-1}$ below $1 \mathrm{~km} \mathrm{MSL}$ during the period of observed turbulence within the warm layer from about 0100 to 0400 UTC, which provides some additional support for the role of turbulence in enhancing warm rain processes. The anomalous trend of increasing fall speeds throughout the warm layer in the MORR simulation is associated with residual melting snow at these low levels. This is linked to the dependence of the melting rate parameterization in MORR on the snow particle size distribution parameters of $\lambda \mathrm{s}$ and $N_{o s}$, which are being skewed toward lower values due to the production of too large of spherical snow particles aloft. Decreases in $\lambda \mathrm{s}$ and $N_{o s}$ lead to weaker melting rates for similar snow concentrations and, consequently, the deeper melting layer in MORR compared to P3 and THOM.

\section{d. Comparison of microphysical processes between lowland and windward regions}

We construct mass content profiles from the microphysical processes by integrating process rates at the model time step within the P3 and MORR schemes for the representative lowland and windward slope sections along the NPOL $54^{\circ}$ azimuthal scan. This assessment aims to provide insight into the microphysical processes that contribute to the discrepancies in cold and warm rain production between the schemes. As expected, P3 predicts much larger accumulated melting mass with a peak over $5 \mathrm{~g} \mathrm{~m}^{-3}$ compared to the MORR scheme over the lowlands during the strong brightband period (2030-2230 UTC 12 November; Figs. 15a,b). Above the peak in $\mathrm{P} 3$ melting mass, accretion processes transfer mass into the rime category via mostly cloud water to ice processes with accumulated mass near $2 \mathrm{~g} \mathrm{~m}^{-3}$, along with a smaller contribution from rain to ice processes. Conversely, nearly all mass from ice-phase accretion processes within the MORR scheme contributes to the snow category, since specified thresholds for transferring accreted mass into the graupel category are not met (Fig. 15b). In particular, the cloud water $>0.5 \mathrm{~g} \mathrm{~m}^{-3}$ threshold for transferring the accreted snow to graupel mass is mostly missed within the scheme. Thus, the peak in accumulated mass to more than $2 \mathrm{~g} \mathrm{~m}^{-3}$ over the lowlands from ice-phase accretion of cloud water processes is nearly all converted to snow mass in MORR.
For deposition, the $\mathrm{P} 3$ scheme predicts a maximum peak at a lower height than in MORR due to the use of a singleice category that includes rimed ice In the liquid-water phase, cloud water accretion by rain within the $\mathrm{P} 3$ scheme is about $0.5 \mathrm{~g} \mathrm{~m}^{-3}$ larger than in the MORR scheme, which is tied to the stronger melting layer and rain fallout in P3 (Figs. 15c,d). The P3 scheme also incorporates a rain condensation parameterization that contributes a nonnegligible rain mass within the warm air.

During the less stable, unblocked flow period, we construct the mass mixing ratio profiles for the 1-h period (0630-0730 UTC 13 November) shown in Fig. 13. The P3 scheme continues to predict a much stronger melting layer peaking near $5 \mathrm{~g} \mathrm{~m}^{-3}$ than in MORR with maximum values around $3 \mathrm{~g} \mathrm{~m}^{-3}$ (Figs. 15e,f), which is related to the significant increase in ice accretion of cloud water and rain processes, and consequently, rime mass production. Ultimately, this larger rime mass is supported by the much stronger depositional processes promoting accumulated ice mass around $3 \mathrm{~g} \mathrm{~m}^{-3}$ near $4 \mathrm{~km}$ MSL within the P3 scheme. Ice-phase accretion of cloud water and rain within the MORR scheme leads to more graupel production compared to earlier, but snow mass is still the overall dominant precipitating ice species over the windward slopes. Although deposition processes are considerably stronger in P3 compared to MORR over both the lowland and windward regions, much of this difference is compensating for the lack of an unrimed precipitating ice category for cloud water accretion, which accounts for much of the snow mass in the MORR scheme. For the liquid-water phase processes, the P3 scheme shows a secondary peak in cloud water accretion in the lowest $1 \mathrm{~km}$ MSL that is missed within the MORR scheme, which is contributing to the warm rain production at the surface. However, both BMPs predict lower accumulated warm rain mass than in the earlier blocked flow period, even though the observations strongly suggest more warm rain during this unblocked period. This implies that the underestimation in the precipitation within the P3 and MORR schemes is at least partly due to missing warm rain production in the model.

\section{Sensitivity experiments}

We conduct several sensitivity experiments of the 12-13 November event focused on the P3 and THOM schemes in an effort to better understand deficiencies in cold and warm rain processes within the BMPs. The following experiments are performed: 1) THOM-sphere specifies the constant $\rho_{s}$ from MORR of $100 \mathrm{~kg} \mathrm{~m}^{-3}$ to modify THOM from a nonspherical to spherical snow parameterization; 2) P3-autoSB substitutes the cloud droplet autoconversion parameterization of 
a)

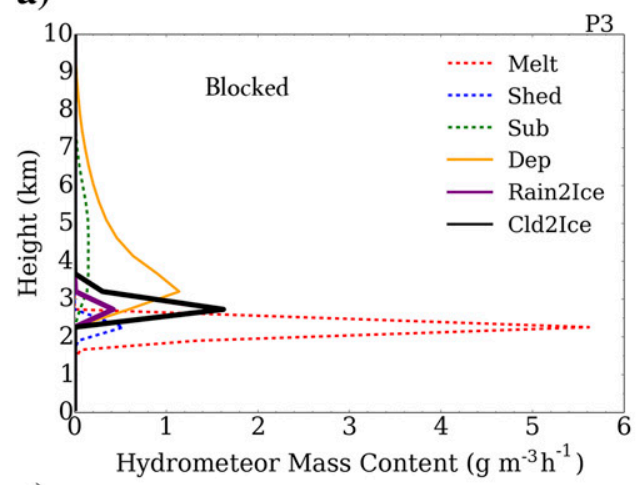

c)

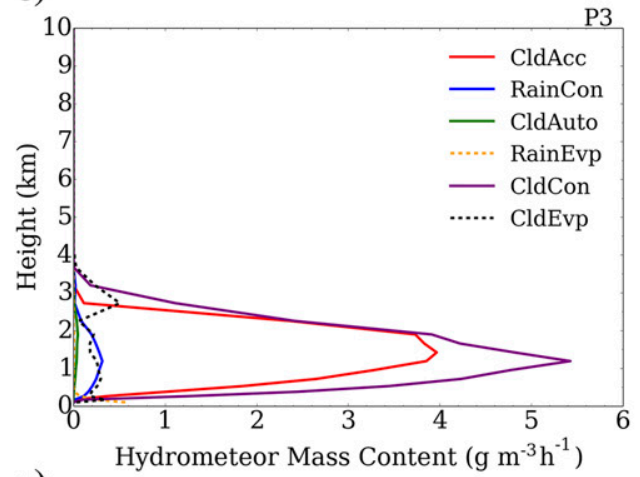

e)

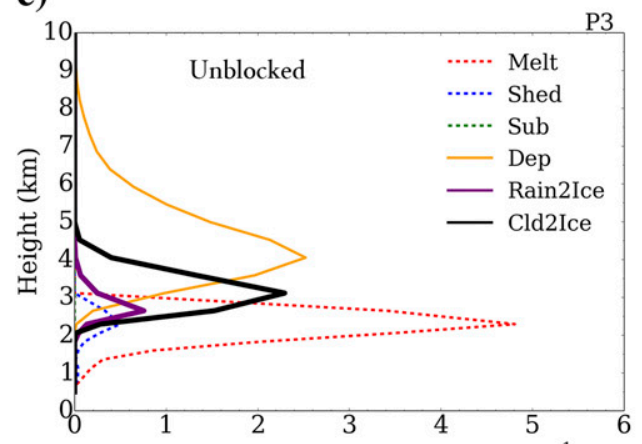

g) Hydrometeor Mass Content $\left(\mathrm{g} \mathrm{m}^{-3} \mathrm{~h}^{-1}\right)$

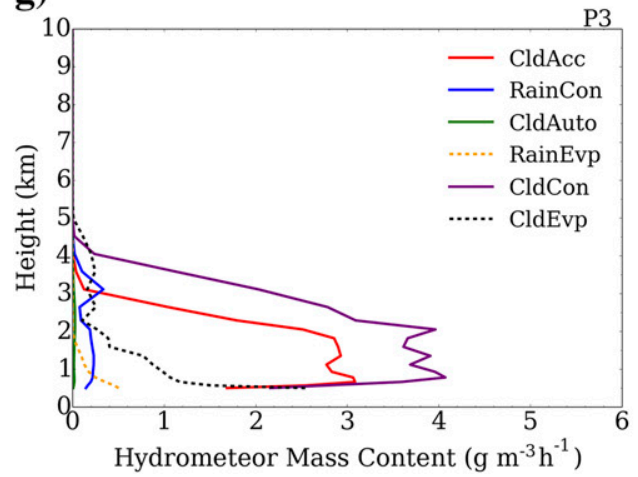

b)

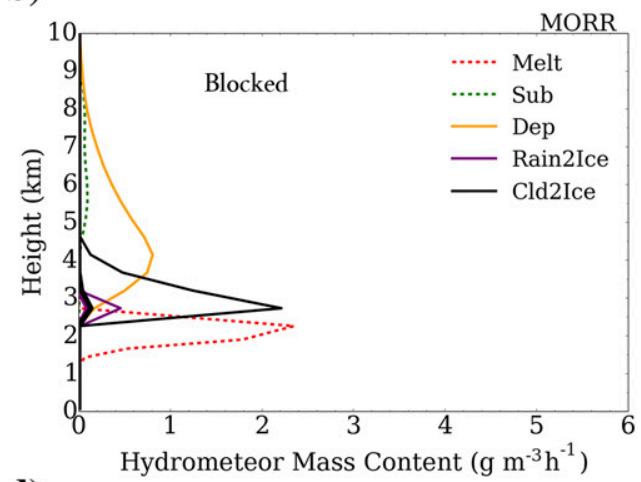

d)

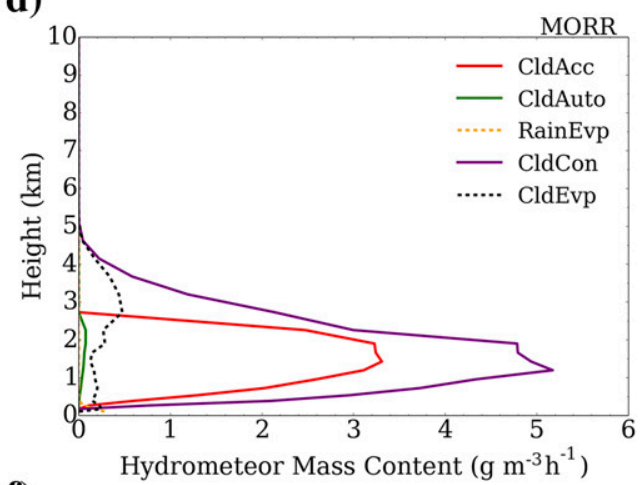

f)

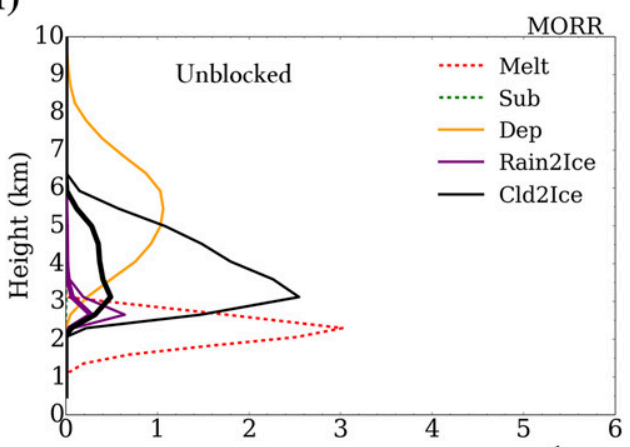

h)

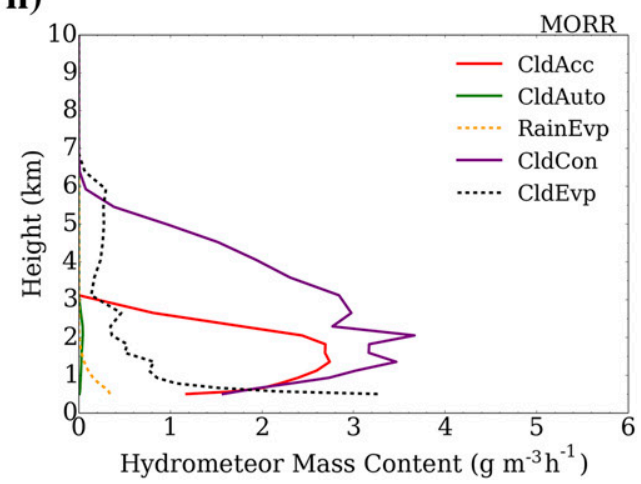

FIG. 15. Averaged vertical profiles of cold microphysical process rates $\left(\mathrm{g} \mathrm{m}^{-3} \mathrm{~h}^{-1}\right)$ along $0-25 \mathrm{~km}$ section of NPOL $54^{\circ}$ azimuthal scan for 2-h period (2030-2230 UTC 12 Nov) during stable blocked flow, rime layer period in (a) P3 and (b) MORR simulations. Cold processes include melting ("Melt"), shedding ("Shed"), sublimation ("Sub"), deposition ("Dep"), conversion of rain to ice ("Rain2Ice"), and conversion of cloud to ice ("Cld2Ice"). We sum the individual process rates associated with ice, snow, and graupel from 
Khairoutdinov and Kogan (2000, hereafter KK00) used in the P3 control run with the Seifert and Beheng (2001, hereafter SB01) parameterization; 3) P3-ccn20 uses a cloud drop concentration of $20 \mathrm{~cm}^{-3}$ instead of the $100 \mathrm{~cm}^{-3}$ set for the $\mathrm{P} 3$ control run; and 4) P3-nudge applies large-scale spectral nudging above the PBL on the WRF 9-km grid to the temperature, water vapor, and wind fields of the GFS reanalysis during the first $12 \mathrm{~h}$ of the simulation through 0000 UTC 13 November. For experiment 2, The key difference between the autoconversion schemes is that SB01 accounts for selfcollection of drops while this process is neglected in KK00.

When comparing the total accumulated precipitation at the lowland and windward sites, rather subtle differences exist between the P3 control and sensitivity simulations (Figs. 16a,b). P3-ccn20 shows the largest precipitation difference from $\mathrm{P} 3$ control of only about $4 \%$. Overall, our suite of P3 runs indicates that possible discrepancies with the assumed $\mathrm{CCN}$ environment (P3-ccn20), prediction of large-scale flow (P3-nudge), and autoconversion parameterization (P3-autoSB), are not significantly contributing to the underestimation in precipitation in the $\mathrm{P} 3$ control run. This result further suggests that WRF resolution issues and neglect of a turbulence parameterization within the BMPs could be important contributing factors to the underprediction. Nevertheless, THOM-sphere shows notable divergence of precipitation from the THOM control run prior to about 0900 UTC 13 November, with larger precipitation rates over the lowlands and smaller precipitation rates over the windward slopes. The opposing trend in precipitation between the lowlands and windward slopes implies that assuming spherical snow in THOM-sphere promoted an increase in precipitation growth and fallout over the lowlands that effectively limited precipitation over the windward slopes. This led to an improved precipitation forecast over the lowlands and a degraded forecast over the windward slopes compared to THOM control.

At the APU Fishery site, the P3-autoSB run significantly overestimates $D_{m}$, while P3-ccn20 more closely represents the observed $D_{m}$ compared to the control run (Fig. 16c), as the lower CCN environment allows for the more efficient production of raindrops and limited growth time prior to fallout compared to the higher $\mathrm{CCN}$ environment. For the THOM runs, the THOM-sphere predicts overall lower $D_{m}$ compared to the control run and poorer agreement to the APU during the blocked flow and dominant cold rain period prior to 0000 UTC 13 November (Fig. 16d).

At the MRR Bishop/CRN site, THOM-sphere simulates much slower fall speeds within the warm layer (Fig. 17a) than the control THOM (i.e., Fig. 14d). This slow transition to faster fall speeds within the warm layer is similar to the trend in fall speeds within the MORR scheme (i.e., Fig. 14c), which provides further evidence of inherent biases in spherical snow parameterizations associated with the production of unrealistically large snow sizes and weaker melting rates. The much stronger fall speeds above the freezing level in THOMsphere compared to the control is due to the efficient production of rimed snow to graupel. The larger graupel contribution within THOM-sphere promotes faster sedimentation into the warm layer and more precipitation over the lowlands compared to the control (i.e., Fig. 16a). P3-autoSB simulates drastically faster fall speeds (Fig. 17b) than the control P3 run (Fig. 14b), as the less efficient warm rain processes in SBU2001 leads to more dominant cold rain processes and larger raindrops at the surface compared to KK00 in the control run. This is illustrated in Fig. 17d by the weaker production of rain from the liquid-phase in P3-autoSB, which allows for more cloud water uptake within and above the melting layer for cold rain production (Fig. 17c) compared to the control (i.e., Figs. 15a,c). The compensating effects of the cold and warm rain processes in the $\mathrm{P} 3$-autoSB run led to similar precipitation totals to the control P3.

\section{Summary and conclusions}

We assessed the ability of the P3, MORR, and THOM BMPs, which implement unique parameterizations and assumptions for simulating liquid and frozen hydrometeors within the WRF Model, to forecast two ARs producing huge precipitation totals over the Olympic Peninsula during November 2015. Although we only present the detailed validation results for the AR on 12-13 November in this paper, we found similar AR

\footnotetext{
MORR to calculate total ice process rates similar to P3. For "Rain2Ice" and "Cld2Ice", the graupel (thick line) and total ice (thin line) categories are shown for MORR. (c),(d) As in (a),(b), but for warm microphysical processes. Warm processes include accretion of cloud liquid water by rain ("CldAcc"), rain condensation ("RainCon"), autoconversion of cloud liquid water to rain ("CldAuto"), rain evaporation ("RainEvp"), cloud condensation ("CldCon"), and cloud evaporation ("CldEvp"). (e)-(h) As in (a)-(d), but along 35-60 km section of NPOL $54^{\circ}$ azimuthal scan for 1-h period (0630-0730 UTC 13 Nov) during less stable, unblocked flow period.
} 

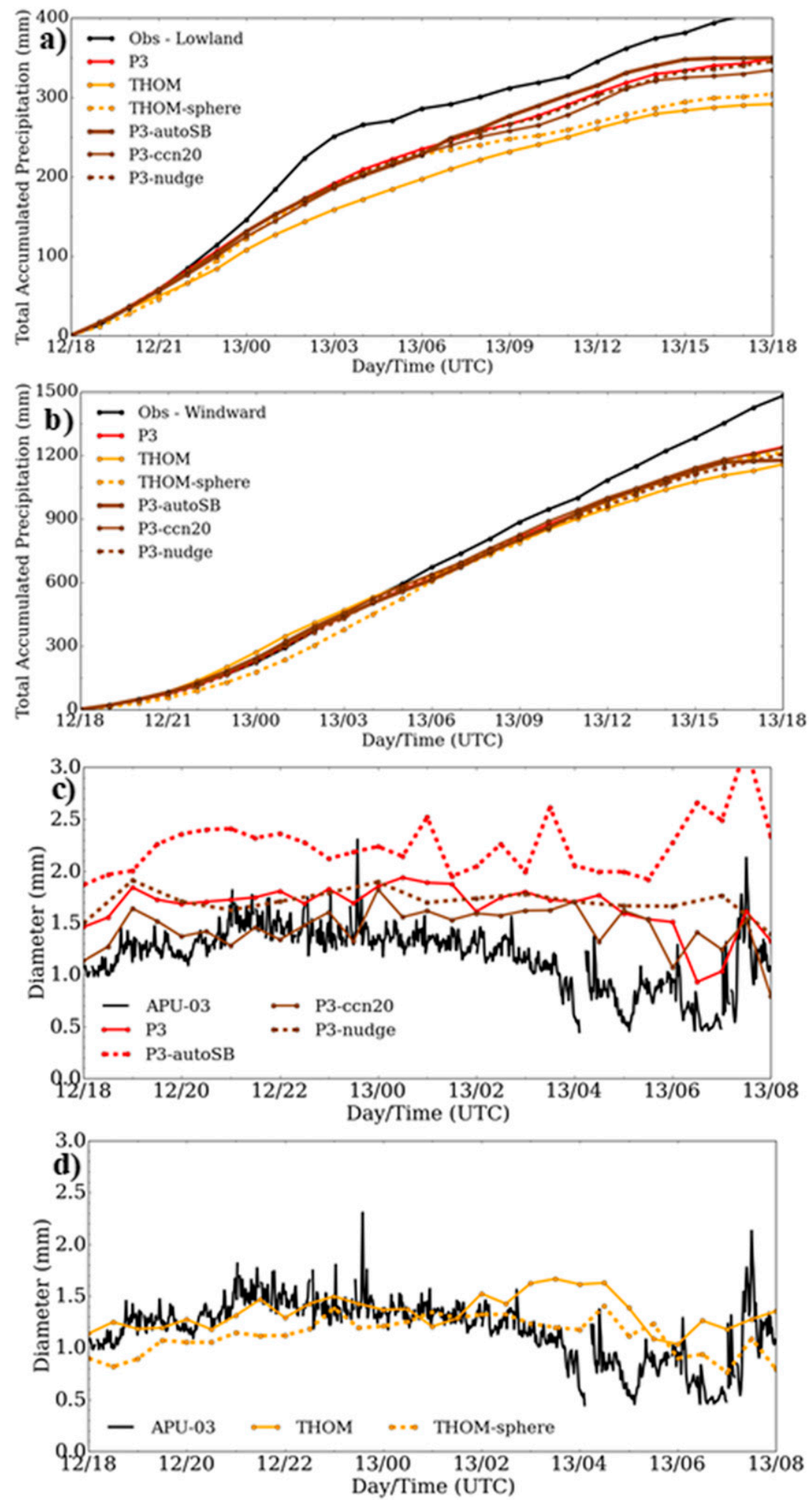

FIG. 16. (a) Lowland and (b) windward observed precipitation time series constructed from site locations denoted in white and blue, respectively, in Fig. 1a. Model precipitation time series constructed using bilinear interpolation of 4 nearest model grid points to site location for P3, THOM, THOM-sphere, P3-autoSB, P3-ccn20, and P3-nudge runs. (c) Mass-weighted mean rain diameters $\left(D_{m}\right)$ from the APU disdrometer at Fishery 

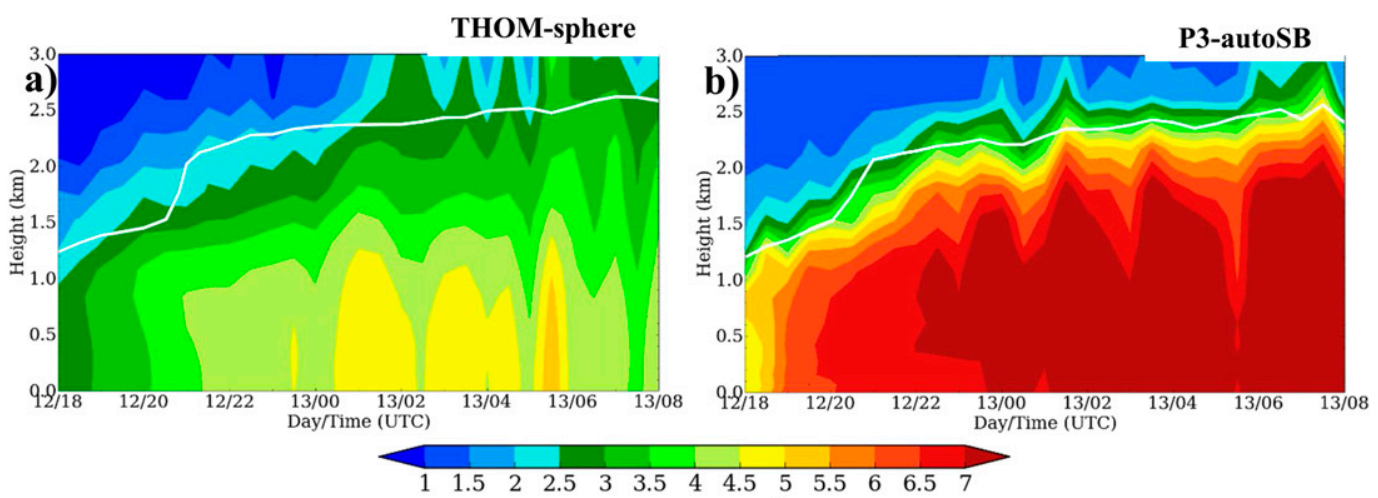

Fall Speed $\left(\mathrm{m} \mathrm{s}^{-1}\right)$
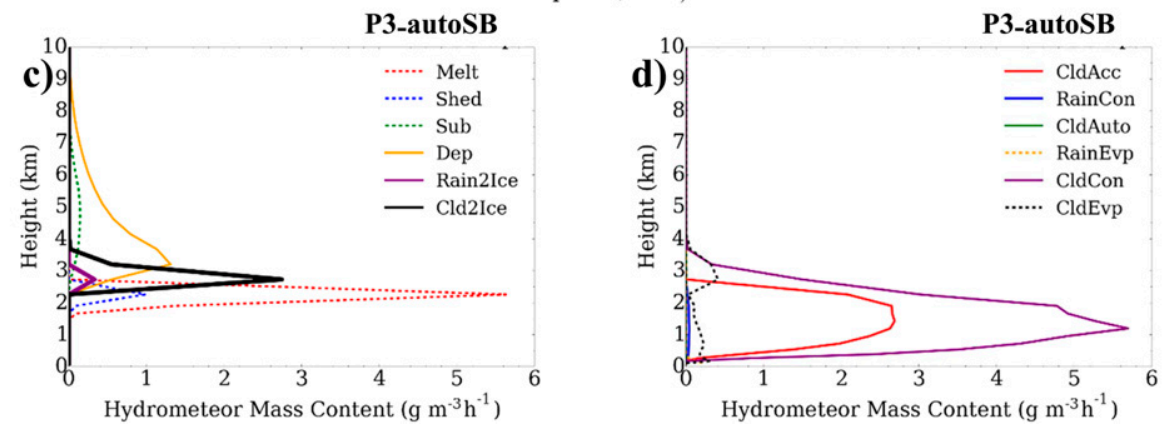

FIG. 17. Mass-weighted bulk mean fall speeds from (a) THOM-sphere and (b) P3-autoSB simulations at Bishop/CRN site (MRR-04) from 1800 UTC 12 Nov to 0800 UTC 13 Nov. Fall speeds are calculated as in Fig. 14. Freezing level $(273.15 \mathrm{~K})$ in simulations denoted by white lines in (a),(b). (c),(d) As in Figs. 14a and 14c, but for P3-autoSB run.

characteristics and BMP results for the 16-17 November event. Overall, all BMP schemes underpredicted precipitation totals during the AR cases, but the P3 scheme showed the lowest underpredictions from $10 \%$ to $23 \%$ over the lowlands and windward slopes. The MORR and THOM schemes underpredicted precipitation by $19 \%-36 \%$ over these regions, albeit THOM showed a slight improvement over MORR. We also conducted sensitivity experiments where different particle shapes, warm rain autoconversion parameterizations, $\mathrm{CCN}$ environments, and specifications of the large-scale atmospheric state, were applied within the P3 and THOM schemes for the 12-13 November AR event. We highlight several key findings from our intensive validation work.

1) The prognostic treatment for predicting varying riming degrees within the single, bulk ice-phase category of the P3 scheme relaxes the requirement for strict thresholding approaches between multiple precipitating ice species as used in the THOM and MORR schemes. Ultimately, this allowed for enhanced rime mass and rime fraction, which promoted higher fall speeds and melting rates, and consequently, larger rain mass and precipitation totals across the lowland and windward slopes of the Olympic Peninsula during the blocked and unblocked flow periods. The strict cloud water threshold of $0.5 \mathrm{~g} \mathrm{~m}^{-3}$ for converting snow to graupel mass in MORR tends to limit the production of rimed particles with faster fall speeds.

2) The spherical snow parameterization within the MORR scheme can influence too large of snow particles and, consequently, unrealistically weak melting rates and slow fall speeds below the melting layer. Faster snow melting rates associated with the nonspherical snow particles within the P3 and THOM schemes promote a more realistic transition to fall speeds in the warm rain layer. Our sensitivity

(APU-03) vs simulated rain diameters within the suite of P3 runs in (a),(b). (d) As in (c), but for the two THOM runs in (a),(b). Bilinear interpolation of 4 nearest model grid points used to calculate rain diameters from BMPs. 
experiment using the spherical snow assumption within the THOM scheme showed a similar trend in fall speeds to MORR.

3) The BMPs underpredicted the contribution of warm rain processes to precipitation rates and accumulations at the surface as the conditions transitioned from blocked to unblocked flow. Enhanced water vapor fluxes associated with the low-level jet were the primary driver of the warm rain production, but our sensitivity experiment using spectral nudging suggested that underrepresentation of water vapor flux was not the major reason for the precipitation deficit in the model. Furthermore, assumption of $\mathrm{CCN}$ environment and choice of warm rain parameterization within the BMPs were not important factors in the precipitation deficit, according to our additional sensitivity experiments. Therefore, the neglect of turbulence parameterizations within BMPs could be an important driver for the too weak of warm rain processes and underprediction in precipitation, as turbulence can stimulate condensational and collisional growth for accelerating the drop size distribution and reducing the formation time of raindrops (Franklin 2008).

4) All BMPs poorly resolve the seeder-feeder process, particularly during partially blocked and unblocked flow conditions over the Olympic Peninsula, when less stable conditions promoted active depositional growth layers aloft and finescale embedded convective cells at lower levels. This interaction between the midand low-level precipitation particles likely influenced larger precipitation rates due to the intensification of cold and warm rain processes. The poor representation of the seeder-feeder process is likely tied to issues with the WRF resolution in resolving the narrow layers of instability associated with the depositional layers and finescale structures of the embedded convection. Nevertheless, limitations in the ice nucleation parameterizations within the BMPs may also be contributing to unrealistically weak deposition processes.

The prognostic riming approach within the $\mathrm{P} 3$ scheme helps improve upon the other BMPs, but all BMPs struggle to accurately transition between these hybrid rain periods. Thus, we encourage future BMP validation work to focus efforts on evolving the prognostic riming approach within the P3 scheme, implementing turbulence parameterizations within BMPs, and pushing the model resolution envelope to better understanding how resolution can impact precipitation forecasts in areas of complex terrain.

Acknowledgments. We thank the reviewers for suggestions to improve the manuscript. Model simulations were conducted on the NASA Discover Cluster. This work was supported by National Aeronautics and Space Administration Grant NNX16AD81G.

\section{REFERENCES}

Barthazy, E., and R. Schefold, 2006: Fall velocity of snowflakes of different riming degree and crystal types. Atmos. Res., 82 , 391-398, https://doi.org/10.1016/j.atmosres.2005.12.009.

Bohne, A. R., 1982: Radar detection of turbulence in precipitation environments. J. Atmos. Sci., 39, 1819-1837, https://doi.org/ 10.1175/1520-0469(1982)039<1819:RDOTIP > 2.0.CO;2.

Colle, B. A., and C. F. Mass, 2000: The 5-9 February 1996 flooding event over the Pacific Northwest: Sensitivity studies and evaluation of the MM5 precipitation forecasts. Mon. Wea. Rev., 128, 593-617, https://doi.org/10.1175/1520-0493(2000) 128<0593:TFFEOT $>2.0$. CO;2.

,$- \ldots$, and K. J. Westrick, 2000: MM5 precipitation verification over the Pacific Northwest during the 1997-99 cool seasons. Wea. Forecasting, 15, 730-744, https://doi.org/10.1175/ 1520-0434(2000)015<0730:MPVOTP > 2.0.CO;2.

— A. Neager, and A. Molthan, 2017: Structure and evolution of a warm frontal precipitation band during the GPM cold season precipitation experiment (GCPEx). Mon. Wea. Rev., 145, 473-493, https://doi.org/10.1175/MWR-D-16-0072.1.

Conrick, R., and C. F. Mass, 2019: An evaluation of simulated precipitation characteristics during OLYMPEX. J. Hydrometeor., 20, 1147-1164, https://doi.org/10.1175/JHM-D-18-0144.1.

$\longrightarrow,-$, and Q. Zhong, 2018: Simulated Kelvin-Helmholtz waves over terrain and their microphysical implications. J. Atmos. Sci., 75, 2787-2800, https://doi.org/10.1175/JAS-D18-0073.1.

Cotton, W. R., G. H. Bryan, and S. C. van den Heever, 2011: Storm and Cloud Dynamics. 2nd ed. Academic Press, 809 pp.

Dettinger, M., 2011: Climate change, atmospheric rivers, and floods in California-A multimodel analysis of storm frequency and magnitude changes. J. Amer. Water Resour. Assoc., 47, 514-523, https://doi.org/10.1111/j.1752-1688.2011.00546.x.

Dolan, B., S. A. Rutledge, S. Lim, V. Chandrasekar, and M. Thurai, 2013: A robust C-band hydrometeor identification algorithm and application to a long-term polarimetric radar dataset. J. Appl. Meteor. Climatol., 52, 2162-2186, https://doi.org/ 10.1175/JAMC-D-12-0275.1.

Durran, D. K., and J. B. Klemp, 1982: On the effects of moisture on the Brunt-Väisälä frequency. J. Atmos. Sci., 39, 2152-2158, https://doi.org/10.1175/1520-0469(1982)039<2152: OTEOMO $>2.0 . \mathrm{CO} ; 2$.

Field, P. R., R. J. Hogan, P. R. A. Brown, A. J. Illingworth, T. W. Choularton, and R. J. Cotton, 2005: Parameterization of ice-particle size distributions for mid-latitude stratiform cloud. Quart. J. Roy. Meteor. Soc., 131, 1997-2017, https://doi.org/10.1256/qj.04.134.

Franklin, C. N., 2008: A warm rain microphysics parameterization that includes the effect of turbulence. J. Atmos. Sci., 65, 17951816, https://doi.org/10.1175/2007JAS2556.1.

Gorgucci, G., V. Chandrasekar, V. N. Bringi, and G. Scarchilli, 2002: Estimation of raindrop size distribution parameters from polarimetric radar measurements. J. Atmos. Sci., 59, 2373-2384, https://doi.org/10.1175/1520-0469(2002)059<2373: EORSDP $>2.0 . \mathrm{CO} ; 2$.

Grell, G. A., and S. R. Freitas, 2014: A scale and aerosol aware stochastic convective parameterization for weather and air quality modeling. Atmos. Chem. Phys., 14, 5233-5250, https:// doi.org/10.5194/acp-14-5233-2014. 
Halder, M., A. Hazra, P. Mukhopadhyay, and D. Siingh, 2015: Effect of the better representation of the cloud ice-nucleation in WRF microphysics schemes: A case study of a severe storm in India. Atmos. Res., 154, 155-174, https://doi.org/10.1016/ j.atmosres.2014.10.022.

Heymsfield, A. J., A. Bansemer, C. Schmitt, C. Twohy, and M. R. Poellot, 2004: Effective ice particle densities derived from aircraft data. J. Atmos. Sci., 61, 982-1003, https://doi.org/ 10.1175/1520-0469(2004)061<0982:EIPDDF>2.0.CO;2.

- - , and M. R. Poellot, 2017: GPM ground validation NCAR particle probes OLYMPEX. NASA Global Hydrology Resource Center DAAC, accessed 13 March 2017, http:// doi.org/10.5067/GPMGV/OLYMPEX/PROBES/DATA201.

Hong, S.-Y., K.-S. S. Lim, Y.-H. Lee, J.-C. Ha, H.-W. Kim, S.-J. Ham, and J. Dudhia, 2010: Evaluation of the WRF double-moment 6-class microphysics scheme for precipitating convection. $A d v$ Meteor., 2010, 707253, https://doi.org/10.1155/2010/707253.

Houze, R., and S. Medina, 2005: Turbulence as a mechanism for orographic precipitation enhancement. J. Atmos. Sci., 62, 3599-3623, https://doi.org/10.1175/JAS3555.1.

— , and Coauthors, 2017: The Olympic Mountains Experiment (OLYMPEX). Bull. Amer. Meteor. Soc., 98, 2167-2188, https://doi.org/10.1175/BAMS-D-16-0182.1.

_ J. Wurman, S. Brodzik and A. Framback, 2018: GPM ground validation Doppler on Wheels (DOW) OLYMPEX V2. NASA Global Hydrology Resource Center DAAC, accessed 14 December 2016, http://doi.org/10.5067/GPMGV/OLYMPEX/ DOW/DATA201.

Iacono, M. J., J. S. Delamere, E. J. Mlawer, M. W. Shephard, S. A. Clough, and W. D. Collins, 2008: Radiative forcing by longlived greenhouse gases: Calculations with the AER radiative transfer models. J. Geophys. Res., 113, D13103, https://doi.org/ 10.1029/2008JD009944.

ICAO, 2010: Meteorological service for international air navigation. Annex 3 to the Convention on International Civil Aviation, 17th ed. ICAO International Standards and Recommended Practices Tech. Annex, 206 pp.

Jaffrain, J., and A. Berne, 2011: Experimental quantification of the sampling uncertainty associated with measurements from PARSIVEL disdrometers. J. Hydrometeor., 12, 352-370, https://doi.org/10.1175/2010JHM1244.1.

Janjić, Z., 1990: The step-mountain coordinate: Physics package. Mon. Wea. Rev., 118, 1429-1443, https://doi.org/10.1175/ 1520-0493(1990)118<1429:TSMCPP > 2.0.CO;2.

- 1994: The step-mountain eta coordinate model: Further developments of the convection, viscous sublayer, and turbulence closure schemes. Mon. Wea. Rev., 122, 927-945, https:// doi.org/10.1175/1520-0493(1994)122<0927:TSMECM>2.0.CO;2.

Khairoutdinov, M., and Y. Kogan, 2000: A new cloud physics parameterization in a large-eddy simulation model of marine stratocumulus. Mon. Wea. Rev., 128, 229-243, https://doi.org/ 10.1175/1520-0493(2000)128<0229:ANCPPI>2.0.CO;2.

Kumjian, M. R., S. Mishra, S. E. Giangrande, T. Toto, A. V. Ryzhkov, and A. Bansemer, 2016: Polarimetric radar and aircraft observations of saggy bright bands during MC3E. J. Geophys. Res. Atmos., 121, 3584-3607, https://doi.org/10.1002/2015JD024446.

Lang, S., W. Tao, J. Chern, D. Wu, and X. Li, 2014: Benefits of a fourth ice class in the simulated radar reflectivities of convective systems using a bulk microphysics scheme. J. Atmos. Sci., 71, 3583-3612, https://doi.org/10.1175/JAS-D-13-0330.1.

Lang, T. J., and N. Guy, 2017: Diagnosing turbulence for research aircraft safety using open source toolkits. Results Phys., 7, 2425-2426, https://doi.org/10.1016/j.rinp.2017.07.015.
Lin, Y., and B. A. Colle, 2009: The 4-5 December 2001 IMPROVE-2 event: Observed microphysics and comparisons with the Weather Research and Forecasting model. Mon. Wea. Rev., 137, 1372-1392, https://doi.org/10.1175/ 2008MWR2653.1.

— and - 2011: A new bulk microphysical scheme that includes riming intensity and temperature-dependent ice characteristics. Mon. Wea. Rev., 139, 1013-1035, https://doi.org/ 10.1175/2010MWR3293.1.

Liu, C.-H., and M. W. Moncrieff, 2007: Sensitivity of cloudresolving simulations of warm-season convection to cloud microphysics parameterizations. Mon. Wea. Rev., 135, 2854-2868, https://doi.org/10.1175/MWR3437.1.

Locatelli, J. D., and P. V. Hobbs, 1974: Fall speeds and masses of solid precipitation particles. J. Geophys. Res., 79, 2185-2197, https://doi.org/10.1029/JC079i015p02185.

Martin, A., F. M. Ralph, R. Demirdjian, L. DeHaan, R. Weihs, J. Helly, D. Reynolds, and S. Iacobellis, 2018: Evaluation of atmospheric river predictions by the WRF Model using aircraft and regional mesonet observations of orographic precipitation and its forcing. J. Hydrometeor., 19, 1097-1113, https://doi.org/10.1175/JHM-D-17-0098.1.

McMurdie, L. A., A. K. Rowe, R. A. Houze Jr., S. R. Brodzik, J. P. Zagrodnik, and T. M. Schuldt, 2018: Terrain-enhanced precipitation processes above the melting layer: Results from OLYMPEX. J. Geophys. Res. Atmos., 123, 12 194-12209, https://doi.org/10.1029/2018JD029161.

Milbrandt, J. A., and H. Morrison, 2016: Parameterization of cloud microphysics based on the prediction of bulk ice particle properties. Part III: Introduction of multiple free categories. J. Atmos. Sci., 73, 975-995, https://doi.org/10.1175/JAS-D-150204.1.

, M. K. Yau, J. Mailhot, S. Bélair, and R. McTaggart-Cowan, 2010: Simulation of an orographic precipitation event during IMPROVE-2. Part II: Sensitivity to the number of moments in the bulk microphysics scheme. Mon. Wea. Rev., 138, 625-642, https://doi.org/10.1175/2009MWR3121.1.

, S. Bélair, M. Faucher, M. Vallée, M. Carrera, and A. Glazer, 2016: The pan-Canadian high resolution $(2.5 \mathrm{~km})$ deterministic prediction system. Wea. Forecasting, 31, 1791-1816, https:// doi.org/10.1175/WAF-D-16-0035.1.

Minder, J. R., D. R. Durran, G. H. Roe, and A. M. Anders, 2008: The climatology of small-scale orographic precipitation over the Olympic Mountains: Patterns and processes. Quart. J. Roy. Meteor. Soc., 134, 817-839, https://doi.org/10.1002/qj.258.

Mitchell, D. L., and A. J. Heymsfield, 2005: Refinements in the treatment of ice particle terminal velocities, highlighting aggregates. J. Atmos. Sci., 62, 1637-1644, https://doi.org/10.1175/JAS3413.1.

Molthan, A. L., and B. A. Colle, 2012: Comparisons of single- and double-moment microphysics schemes in the simulation of a synoptic-scale snowfall event. Mon. Wea. Rev., 140, 2982-3002, https://doi.org/10.1175/MWR-D-11-00292.1.

Morrison, H., and J. A. Milbrandt, 2015: Parameterization of cloud microphysics based on the prediction of bulk ice particle properties. Part I: Scheme description and idealized tests. J. Atmos. Sci., 72, 287-311, https://doi.org/10.1175/JAS-D-14-0065.1.

, G. Thompson, and V. Tatarskii, 2009: Impact of cloud microphysics on the development of trailing stratiform precipitation in a simulated squall line: Comparison of one- and two-moment schemes. Mon. Wea. Rev., 137, 991-1007, https://doi.org/10.1175/ 2008MWR2556.1.

, J. A. Milbrandt, G. H. Bryan, K. Ikeda, S. A. Tessendorf, and G. Thompson, 2015: Parameterization of cloud microphysics 
based on the prediction of bulk ice particle properties. Part II: Case study comparisons with observations and other schemes. J. Atmos. Sci., 72, 312-339, https://doi.org/10.1175/JAS-D-140066.1.

Naeger, A., B. A. Colle, and A. Molthan, 2017: Evaluation of cloud microphysical schemes for a warm frontal snowband during the GPM Cold Season Precipitation Experiment (GCPEx). Mon. Wea. Rev., 145, 4627-4650, https://doi.org/10.1175/ MWR-D-17-0081.1.

Neiman, P. J., L. J. Schick, F. M. Ralph, M. Hughes, and G. A. Wick, 2011: Flooding in western Washington: The connection to atmospheric rivers. J. Hydrometeor., 12, 1337-1358, https:// doi.org/10.1175/2011JHM1358.1.

Peters, G., B. Fischer, H. Münster, M. Clemens, and A. Wagner, 2005: Profiles of raindrop size distributions as retrieved by microrain radars. J. Appl. Meteor., 44, 1930-1949, https:// doi.org/10.1175/JAM2316.1.

Petersen, W. A., and P. N. Gatlin, 2017: GPM ground validation Micro Rain Radar (MRR) OLYMPEX. NASA Global Hydrology Resource Center DAAC, accessed 1 December 2017, http://doi.org/10.5067/GPMGV/OLYMPEX/MRR/DATA201.

, A. Tokay, and P. N. Gatlin, 2017a: GPM ground validation pluvio precipitation gauges OLYMPEX. NASA Global Hydrology Resource Center DAAC, accessed 5 January 2018, http:// doi.org/10.5067/GPMGV/OLYMPEX/PLUVIO/DATA301.

,,--- , and M. T. Wingo, 2017b: GPM ground validation Autonomous Parsivel Unit (APU) OLYMPEX. NASA Global Hydrology Resource Center DAAC, accessed 1 December 2017, http://doi.org/10.5067/GPMGV/OLYMPEX/APU/DATA301.

, D. Wolff, J. Wang, and A. Tokay, 2017c: GPM ground validation Met One rain gauge pairs OLYMPEX. NASA Global Hydrology Resource Center DAAC, accessed 1 December 2017, http://doi.org/10.5067/GPMGV/OLYMPEX/GAUGES/ DATA201.

Pinto, J. O., J. A. Grim, and M. Steiner, 2015: Assessment of the high-resolution Rapid Refresh model's ability to predict mesoscale convective systems using object-based evaluation. Wea. Forecasting, 30, 892-913, https://doi.org/10.1175/WAFD-14-00118.1.

Poellot, M. R., A. J. Heymsfield and A. Bansemer, 2017: GPM ground validation UND citation cloud microphysics OLYMPEX. NASA Global Hydrology Resource Center DAAC, accessed 2 November 2016, http://doi.org/10.5067/GPMGV/OLYMPEX/ MULTIPLE/DATA201.

Purnell, D. J., and D. J. Kirshbaum, 2018: Synoptic control over orographic precipitation distributions during the Olympic Mountains Experiment (OLYMPEX). Mon. Wea. Rev., 146, 1023-1044, https://doi.org/10.1175/MWR-D-17-0267.1.

Ralph, F. M., P. J. Neiman, G. A. Wick, S. I. Gutman, M. D. Dettinger, D. R. Cayan, and A. B. White, 2006: Flooding on California's Russian River: Role of atmospheric rivers. Geophys. Res. Lett., 33, L13801, https://doi.org/10.1029/ 2006GL026689.
- E. Sukovich, D. Reynolds, M. Dettinger, S. Weagle, W. Clark, and P. J. Neiman, 2010: Assessment of extreme quantitative precipitation forecasts and development of regional extreme event thresholds using data from HMT-2006 and COOP observers. J. Hydrometeor., 11, 1286-1304, https://doi.org/10.1175/2010JHM1232.1.

Rutledge, S. A., K. Young, H. Voemel, D. Hudak, and P. Rodriguez, 2018: GPM ground validation upper air radiosonde OLYMPEX. NASA Global Hydrology Resource Center DAAC, accessed 1 September 2018, http://doi.org/10.5067/GPMGV/OLYMPEX/ RADIOSONDES/DATA101.

Seifert, A., and K. D. Beheng, 2001: A double-moment parameterization for simulating autoconversion, accretion, and self-collection. Atmos. Res., 59-60, 265-281, https:// doi.org/10.1016/S0169-8095(01)00126-0.

Shi, J. J., and Coauthors, 2010: WRF simulations of the 20-22 January 2007 snow events over eastern Canada: Comparison with in situ and satellite observations. J. Appl. Meteor. Climatol., 49, 2246-2266, https://doi.org/10.1175/2010JAMC2282.1.

Skamarock, W. C., and Coauthors, 2008: A description of the Advanced Research WRF version 3. NCAR Tech. Note NCAR/TN-475+STR, 113 pp., https://doi.org/10.5065/ D68S4MVH.

Strapp, J. W., F. Albers, A. Reuter, A. V. Korolev, U. Maixner, E. Rashke, and Z. Vukovic, 2001: Laboratory measurements of the response of a PMS OAP-2DC. J. Atmos. Oceanic Technol., 18, 1150-1170, https://doi.org/10.1175/1520-0426(2001) 018<1150:LMOTRO > 2.0.CO;2.

Tewari, M., and Coauthors, 2004: Implementation and verification of the unified Noah land surface model in the WRF model. 20th Conf. on Weather Analysis and Forecasting/16th Conf. on Numerical Weather Prediction, Seattle, WA, Amer. Meteor. Soc., 14.2A, https://ams.confex.com/ams/84Annual/techprogram/ paper_69061.htm.

Thompson, G., P. R. Field, R. M. Rasmussen, and W. D. Hall, 2008: Explicit forecasts of winter precipitation using an improved bulk microphysics scheme. Part II: Implementation of a new snow parameterization. Mon. Wea. Rev., 136, 5095-5115, https://doi.org/10.1175/2008MWR2387.1.

Tokay, A., D. B. Wolff, and W. A. Petersen, 2014: Evaluation of the new version of the laser-optical disdrometer, OTT Parsivel ${ }^{2}$. J. Atmos. Oceanic Technol., 31, 1276-1288, https://doi.org/ 10.1175/JTECH-D-13-00174.1.

Wolff, D., D. Marks, W. A. Petersen, and J. Pippit, 2017: GPM ground validation NASA S-Band Dual Polarimetric (NPOL) Doppler Radar OLYMPEX. NASA Global Hydrology Resource Center DAAC, accessed 11 July 2018, http:// doi.org/10.5067/GPMGV/OLYMPEX/NPOL/DATA301.

Zagrodnik, J. P., L. A. McMurdie, and R. A. Houze, 2018: Stratiform precipitation processes in cyclones passing over a coastal mountain range. J. Atmos. Sci., 75, 983-1004, https:// doi.org/10.1175/JAS-D-17-0168.1. 